\title{
Spatio-Temporal Analysis of Climate Change Impact on Future Wind Power Potential in Burundi (East Africa)
}

\author{
Manirakiza Célestin ${ }^{1}$, Lawin Agnidé Emmanuel${ }^{2}$, Lamboni Batablinlè̀1, Niyongendako Marc1 \\ ${ }^{1}$ Institute of Mathematics and Physical Sciences, University of Abomey-Calavi, Porto-Novo, Benin \\ ${ }^{2}$ Laboratory of Applied Hydrology, National Institute of Water, University of Abomey-Calavi, Abomey-Calavi, Benin \\ Email: *manirakiza_celest@yahoo.fr
}

How to cite this paper: Célestin, M., Emmanuel, L.A., Batablinlè, L. and Marc, N. (2019) Spatio-Temporal Analysis of Climate Change Impact on Future Wind Power Potential in Burundi (East Africa). American Journal of Climate Change, 8, 237-262.

https://doi.org/10.4236/ajcc.2019.82014

Received: February 7, 2019

Accepted: June 3, 2019

Published: June 6, 2019

Copyright $\odot 2019$ by author(s) and Scientific Research Publishing Inc. This work is licensed under the Creative Commons Attribution International License (CC BY 4.0).

http://creativecommons.org/licenses/by/4.0/

\begin{abstract}
This paper assessed climate change impact on future wind power potential across highlands and western lowlands of Burundi. Hourly observed and MERRA-2 data were considered for the historical period 1980-2016, and a Multi-model ensemble for future projections data of eight selected Regional Climate Models under RCP 4.5 and RCP 8.5 over the periods 2019-2040 and 2071-2100 was used. Variability and trend analysis were adopted using standardized index and Mann-Kendall's test, respectively while wind power density (WPD) in quartiles was adopted for changes distribution. As results, diurnal wind speeds (WS) were higher from 9:00 AM to 2:00 PM, while monthly wind speeds reached the maximum during summer time. An increasing trend in WPD was detected all over the studied area. Over the period 2019-2040, the lowest WPD change is projected at Northern Highlands (NHL) under RCP 4.5 with $28.04 \mathrm{~W} \cdot \mathrm{m}^{-2}$ while the highest WPD change of $47.35 \mathrm{~W} \cdot \mathrm{m}^{-2}$ is projected under RCP 8.5 at Southern Imbo plain (SIP). As for the period 2071-2100, the highest change is expected at SIP under RCP 8.5 with $152.39 \mathrm{~W} \cdot \mathrm{m}^{-2}$ while the minimum change of $83.96 \mathrm{~W} \cdot \mathrm{m}^{-2}$ is projected under RCP 4.5 at NHL. The findings showed that areas nearby the Lake Tanganyika are expected to have high positive WDP changes.
\end{abstract}

\section{Keywords}

Burundi, Wind Power, Changes, Future Climate

\section{Introduction}

Climate influences the world through changing temperature, precipitation, snowmelt, and a host of other natural phenomena [1]. Effects of climate change 
vary from one region to another depending on various socio-economic and environmental factors [2]. Globally, mean surface air temperature has risen by about $0.74^{\circ} \mathrm{C} \pm 0.18^{\circ} \mathrm{C}$ during the twentieth century and is projected to rise by $1.8^{\circ} \mathrm{C}-4.0^{\circ} \mathrm{C}$ in the twenty-first century [3]. Extreme precipitations are also projected to increase significantly, especially in regions that are already wet under the current climate conditions, whereas dry spells are predicted to increase particularly in regions characterized by dry weather conditions in the current climate [2]. Furthermore, climate change is predicted to cause stronger surface wind speed values across the boreal regions of the Northern Hemisphere, including much of Canada, Siberia and northern Europe, and in tropical and subtropical regions in Africa, and Central and South America. However, Greenland, southern Europe, China, India, southern Australia and much of the west coast of South America are expected to experience decreasing wind speed values [4].

In energy sector, to mitigate climate change impacts, renewable sources have received considerable attention in power generation due to the growing public concern about the environmental degradation caused by conventional electricity generation and also due to the urgent need in exploring the possibilities of using alternative energy sources [5]. Among the various alternative sources of energy, the wind energy is the fastest growing and most promising renewable energy source as it is proved to be economically viable and commercialized [6] [7]. It does not pollute the environment and it is an endless and a free primary source. Therefore, the increasing demand for renewable energy sources in the coming decades requires that we have a clear understanding of accessible wind resources, and the susceptibility of these resources to climate change [8] [9].

In East Africa, wind energy, which remains hitherto untapped, appears promising in solving the problem of electricity shortage. For example, in Tanzania, Kainkwa [10] reported that the wind energy available in some locations in the northern part of the country was sufficient to generate electricity. Therefore, the acute shortage of electricity that prevails during the dry season could be alleviated to a large extent. Moreover, in Kenya, Peter [11] reported that Kenya has a proven wind energy potential of as high as $346 \mathrm{~W} \cdot \mathrm{m}^{-2}$ and wind speeds of 6 $\mathrm{m} \cdot \mathrm{s}^{-1}$ and above. Thus, the implementation of wind energy projects would significantly reduce the country's dependence on hydropower generation (around $50 \%$ ) which drops quite significantly during dry seasons.

Burundi is an East African country heavily dependent on hydropower for his electricity production and experiences power shortage during the dry seasons [12]. To supplement the shortfall of electricity fossil fuels have become an alternative solution [13]. In fact, the fossil fuels produce a lot of harmful emissions to our environment. Thus, renewable energy sources such as wind, if thoroughly investigated, could be used to a large extent to reduce the dependence of fossil fuels in electricity generation during the dry seasons. Unfortunately, in Burundi, there are no many studies conducted to analyze projected wind power potential. However, according to Collins et al. [14], the climate change models predict that Burundi would experience more extreme weather conditions in the future cha- 
racterized by high winds, hail, and extended droughts. Furthermore, Lawin et al. [15] detected increase in projected wind speed over the period 2021-2050 at Bujumbura station. But, neither of the studies analyzed projected wind power potential over the highlands and western lowlands. Therefore, this paper aims to revisit projected wind speeds and analyze impacts of wind speeds changes on projected wind power potential by considering four sites from two contrasting regions; western lowlands and highlands of Burundi. It fills then the gap by investigating changes in projections over near future (2019-2040) and far future (2071-2100) across highlands and western lowlands of Burundi where wind energy has not yet been extensively analyzed to date. Specifically, the study focuses on analyzing projected changes in wind speeds and evaluates their implication on projected wind power potential across Northern Highlands (NHL), Northern Imbo Plain (NIP), Southern Highlands (SHL) and Southern Imbo Plain (SIP).

\section{Materials and Methods}

\subsection{Study Area}

Figure 1 shows the study area location in Burundi, an East African country

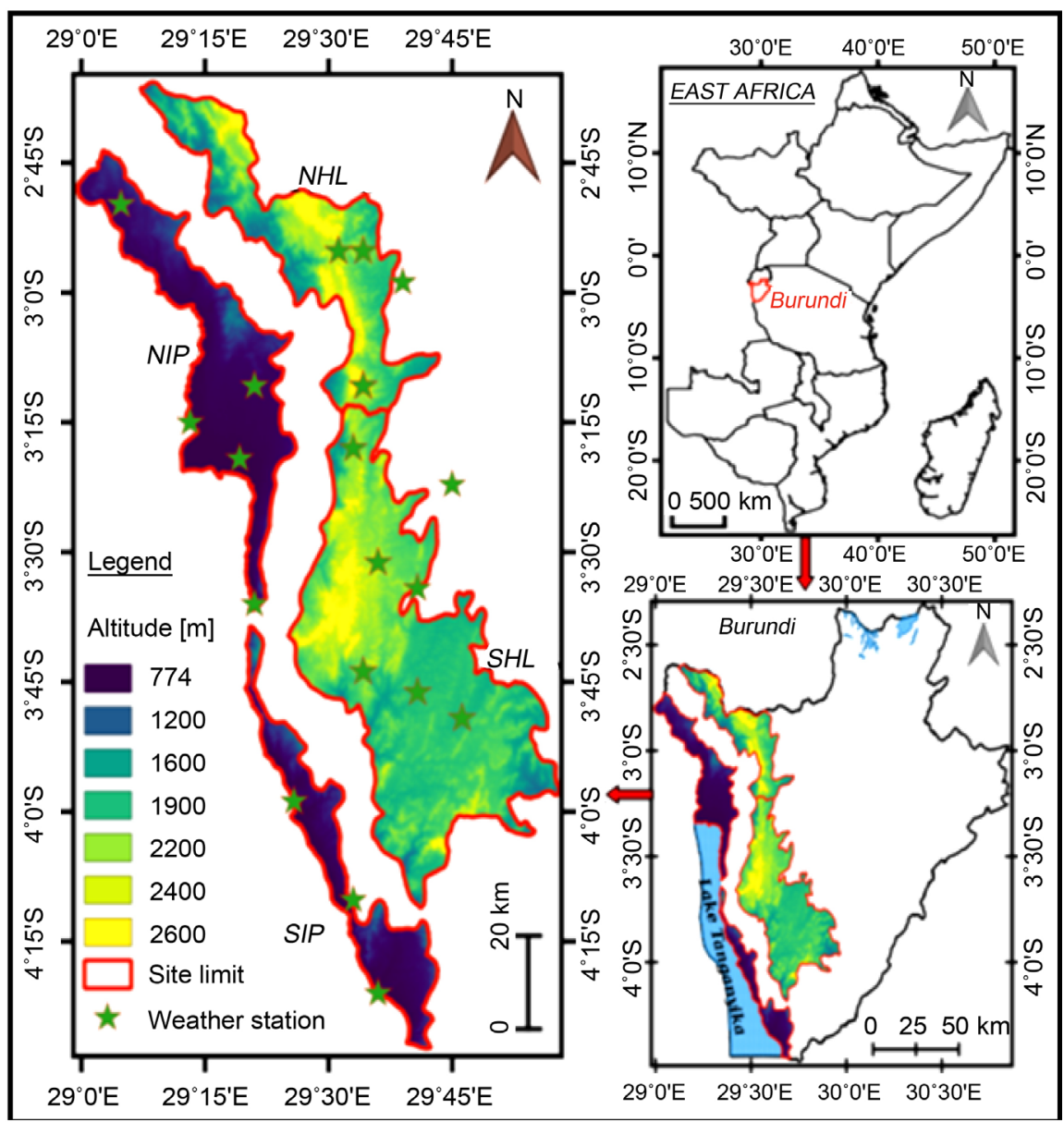

Figure 1. Study area location. 
between longitudes $28.8^{\circ} \mathrm{E}$ and $30.9^{\circ} \mathrm{E}$ and latitudes $2.3^{\circ} \mathrm{S}$ and $4.45^{\circ} \mathrm{S}$ [16]. Bounded to the north by Rwanda, to the East and South by Tanzania and to the West by the Democratic Republic of the Congo (DRC), Burundi covers an area of $27,834 \mathrm{~km}^{2}$ [17]. The study area elevation is between 1800 and $2650 \mathrm{~m}$ altitude in the highlands while lowlands are between 774 and $1100 \mathrm{~m}$ altitude. The annual rainfall in the high altitude regions is almost the double that of low altitudes. Average maximum annual temperatures range from $21.8^{\circ} \mathrm{C}$ to $29.5^{\circ} \mathrm{C}$. Burundi has average wind speeds varying between $4 \mathrm{~m} \cdot \mathrm{s}^{-1}$ and $6 \mathrm{~m} \cdot \mathrm{s}^{-1}$ [18]. The study regions are highlands and western lowlands of Burundi. For better analysis, the highlands were divided into Northern Highlands (NHL) and Southern Highlands (SHL) while the western lowlands were split into Northern Imbo Plain (NIP) and Southern Imbo Plain (SIP).

\subsection{Data Used}

Three sets of data are used in this study. The first set consists of observed data collected from the synoptic stations of Burundi belonging to the Geographical Institute of Burundi (IGEBU). In fact, nineteen meteorological stations have been considered over the historical period 1980-2016 and the concise information on their location are presented in Figure 1. Wind speed observed data were collected at hourly scales. The selection of the time series data was based on the quality of the data collected from various stations. However, only the station of Bujumbura (Airport) was able to cover the considered period 1980-2016, a period which respects the normal of 30 years at least, recommended by World Meteorology Organization (WMO).

To complement observed values at hourly scales, the second set of data grouping MERRA-2 (Modern Era Reanalysis for Research and Applications Version 2) data available online at

https:/gmao.gsfc.nasa.gov/reanalysis/MERRA-2/ was used. This data set is very useful in view of the fact that weather stations are limited in number, unevenly distributed, have missing data problem and short period of observation [19]. Missing observed data have been filled using cross validation method following Ioannis [20]. Table 1 presents the statistical summary of the used data at annual scale.

The third set of used data groups wind speeds from eight Regional Climate Models. These data are available in the context of the COordinated Regional

Table 1. Description of used data over the period 1980-2016 at annual scale.

\begin{tabular}{cccccc}
\hline Variable & Region & Minimum & Maximum & Mean & Standard deviation \\
\hline WS $^{+}$ & NHL & 3.8 & 4.8 & 4.2 & 0.216 \\
& NIP & 3.6 & 4.7 & 4.1 & 0.221 \\
& SHL & 3.8 & 4.9 & 4.3 & 0.231 \\
& SIP & 4.3 & 5.3 & 4.8 & 0.221 \\
\hline
\end{tabular}

${ }^{+} \mathrm{WS}=$ Wind speed in $\left(\mathrm{m} \cdot \mathrm{s}^{-1}\right)$. 
Climate Downscaling Experiment (CORDEX) over Africa at $0.44^{\circ}$ resolution for the period 1950 to 2100 [21] and accessed online (https://www.cordex.org) through user registration. Table 2 shows the climatic models used to generate the multi-model ensemble, where the third column gives their acronyms adopted in this paper. Two experiments performed following the stabilization and the most extreme IPCC Representative Concentration Pathways scenarios (RCP 4.5 and RCP 8.5) for the periods 2019-2040 and 2071-2100 in CORDEX database have been considered. RCP 4.5 is a scenario that stabilizes radiative forcing at $4.5 \mathrm{~W} \cdot \mathrm{m}^{-2}$ in the year 2100 without ever exceeding that value and thus assumes the imposition of emissions mitigation policies. The RCP 8.5 is based on the A2r scenario which combines assumptions about high population and relatively slow income growth with modest rates of technological change and energy intensity improvements, leading in the long-term to high energy demand and greenhouse gas emissions in the absence of climate change policies [22]. This set of data is the most up-to-date ensemble of high-resolution Regional Climate Model (RCM) projections. RCM historical data have been used for bias correction. The eight selected models have already been used over Burundi for climate projection [15] [23].

The data presented in Table 1 are at $12 \mathrm{~m}$ height, the height at which IGEBU data were collected. The MERRA-2 and RCM wind speed data were however at $10 \mathrm{~m}$ height and the power law was used for data extrapolation at $12 \mathrm{~m}$ height [24].

\subsection{Methods}

The historical climate evaluation was conducted over the period 1980-2016 at hourly scale, seasonal scale and interannual scale. The diurnal analysis of the wind speed and wind direction was done from 7:00 AM to 6:00 PM while the nocturnal analysis was performed from 7:00 PM to 6:00 AM. Furthermore, the spatial distribution of WS and WPD has been adopted using Inverse Distance Weighted (IDW) interpolation method [25].

Table 2. Climatic models used.

\begin{tabular}{cccc}
$\begin{array}{c}\text { Global Climate Model } \\
\text { Name }\end{array}$ & Institute ID & $\begin{array}{c}\text { Model Short } \\
\text { Name }\end{array}$ & $\begin{array}{c}\text { Model Origin } \\
\text { Country }\end{array}$ \\
\hline CanESM2 & CCCma & CCCma & Canada \\
CNRM-CM5 & CNRM-CERFACS & CNRM & France \\
EC-EARTH & ICHEC & ICHEC & Europe \\
IPSL-CM5A-MR & IPSL & IPSL & France \\
MIROC5 & MIROC & MIROC & Japan \\
MPI-ESM-LR & MPI-M & MPI & Germany \\
NorESM1-M & NCC & NCC & Norway \\
GFDL-ESM2M & NOAA-GFDL & NOAA & USA \\
\hline
\end{tabular}




\subsubsection{Bias Correction Method and Change Signal Detection}

In this study, Empirical Statistical Downscaling (ESD) and Quantile Delta Mapping (QDM) methods were used for bias correction of RCM data. ESD took wind speed data from $0.44^{\circ}$ resolution $(\sim 50 \mathrm{~km} \times 50 \mathrm{~km})$ to local climate, while QDM method served to bias adjust and detect changes. This computation was respectively implemented using ESD [26] and MBC package [27] in R program [28]. QDM preserves model-projected change signal in quantiles, while at the same time correcting systematic biases in quantiles of a modeled series with respect to observed values [29]. The conservation of changes follows directly from the quantile perturbation [30] and quantile delta change [31] methods, both of which apply simulated changes in quantiles overtop observed historical series [29].

\subsubsection{Variability Analysis}

The discrimination of years with high and low wind speeds was done using the standardized variable index $(I)$ created by Mckee et al. [32] and which can be found in many articles [33] [34]:

$$
I(i)=\frac{\phi_{i}-\bar{\phi}_{m}}{\sigma},
$$

where $\phi_{i}, \bar{\phi}_{m}$ and $\sigma$ are respectively the value for the year $i$, the average and the standard deviation of the time series. Thus, in this paper, a year is considered normal if its index is included between -0.5 and +0.5 . It is in high wind speeds if its index is greater than +0.5 and low wind speeds below -0.5 . This interval remains criticized since it is relatively weak. But it clearly makes it possible to discriminate years with low wind speeds from years with high wind speeds. The standardized variable index also makes it possible to analyze the interannual variability of the key variable at considered spatial scales [15].

\subsubsection{Wind Power Density}

The wind speed data have been used to estimate the wind power, as follows [35]:

$$
W P=\frac{1}{2} \rho A \phi^{3},
$$

Here $W P$ is the power of the wind (in W), $\rho$ is the air density (in $\mathrm{kg} \cdot \mathrm{m}^{-3}$ ), $A$ is the swept area $\left(\right.$ in $^{2}$ ) and $\phi$ is the wind speed (in $\mathrm{m} \cdot \mathrm{s}^{-1}$ ).

Therefore, the wind power density $W P D\left(\right.$ in $\mathrm{W} \cdot \mathrm{m}^{-2}$ ) is given by the following equation:

$$
W P D=\frac{1}{2} \rho \phi^{3},
$$

\subsubsection{Air Density}

The air density $\rho$ was computed as follows:

$$
\rho=\frac{P}{R T},
$$

where $P$ is the atmospheric pressure (in $\mathrm{mb}$ ), $R$ is the universal gas constant 
$\left(=287 \mathrm{~J} \cdot \mathrm{kg}^{-1} \cdot \mathrm{K}^{-1}\right)$ and $T$ is the air temperature (in $\left.\mathrm{K}\right)$.

\subsubsection{Turbulence Intensity}

Wind turbulence is an important site characteristic, because high turbulence levels may decrease the power output and cause extreme loading on the wind turbine components. The turbulence intensity $T I$ is defined as follows [36]:

$$
T I=\frac{\sigma}{\bar{\phi}_{m}}
$$

where $\sigma$ is the standard deviation and $\bar{\phi}_{m}$ is the average wind speed. In this paper, a $T I$ value less than or equal to 0.10 is considered as indicating a low level of turbulence. $T I$ value of 0.25 indicates moderate turbulence while a $T I$ greater than 0.25 is considered as a high level of turbulence at the site.

\subsubsection{Trend Analysis}

For trend analysis, the Mann-Kendall's (MK) test (1945) [37] [38] was used at the threshold $\alpha=0.05$. This trend test is worldwide used in meteorological variables trend detection [15] [39] [40] [41].

\section{Results and Discussions}

\subsection{Wind Power Potential Analysis in the Historical Climate}

\subsubsection{MERRA-2 and RCM Performance}

Figure 2 shows MERRA-2 performance to complement observed data and RCM performance to reproduce historical climate after bias correction. Indeed, the performance was measured with an objective method based on error function, which defines the goodness of fit, the Nash efficiency criterion, $R^{2}$. Therefore,

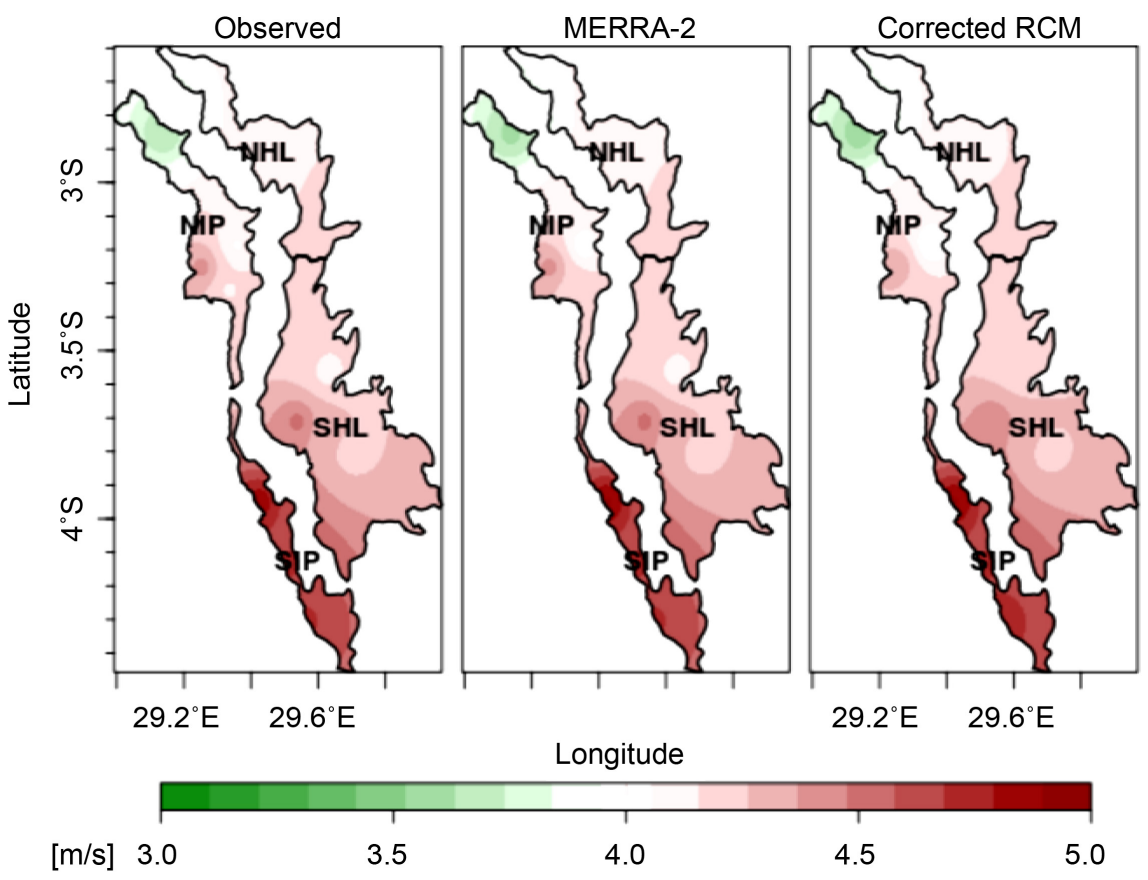

Figure 2. MERRA-2 and bias corrected RCM performance. 
$\mathrm{R}^{2}$ value of 0.95 was found between the ground data and MERRA-2 data used for each site. Furthermore, $\mathrm{R}^{2}$ values of $0.95,0.94,0.92$ and 0.95 were found at NHL, NIP, SHL and SIP, respectively between MERRA- 2 and bias corrected RCM over the period 1980-2016.

\subsubsection{Diurnal and Nocturnal Wind Speed and Wind Direction}

Figure 3 presents average diurnal and nocturnal wind speed and wind direction at NHL over the period 1980-2016. The daywise average wind direction is East-South-East (ESE) with a frequency around $92 \%$. The analysis revealed three parts of the wind rose where $25 \%$ of the winds blow with speeds below $4 \mathrm{~m} \cdot \mathrm{s}^{-1}$, $25 \%$ with speeds between 4 and $6 \mathrm{~m} \cdot \mathrm{s}^{-1}$ while $42 \%$ have speeds between 6 and 7.7 $\mathrm{m} \cdot \mathrm{s}^{-1}$. The feature (NHL (day)) points out that during the day, the highest wind speed value is observed at 8 (or 2:00 PM) while the lowest wind speed value is observed at 1 (or 7:00 AM). Furthermore, the feature (NHL (day)) reveals the increase in the wind speeds from 1 to the $8^{\text {th }}$ hour and the decline of the wind speeds from 8 to 12 . On the other hand, nocturnal winds point three directions, South-East (SE), South-South-East (SSE) and South (S). From the S blow winds with speeds between 2 and $4 \mathrm{~m} \cdot \mathrm{s}^{-1}$ with a frequency of $32 \%$. The wind blowing from the SSE has the speed between 2 and $4 \mathrm{~m} \cdot \mathrm{s}^{-1}$ with a frequency of $18 \%$. Moreover, from the SE blows winds with a frequency of $50 \%$ where $80 \%$ and $20 \%$ of the winds respectively have speeds between 2 and $4 \mathrm{~m} \cdot \mathrm{s}^{-1}$, and speeds between 4 and $4.5 \mathrm{~m} \cdot \mathrm{s}^{-1}$. The analysis of the feature (NHL(night)) reveals that the highest wind speed value at night is observed at 10 (or 4:00 AM) while from 3 to the $8^{\text {th }}$ hour, we observe the lowest wind speeds. Comparing the day with the night, diurnal wind speeds are much higher than nightwise wind speeds. These findings show at which time of the day or night a given wind power turbine can expect receiving the maximum wind speeds.
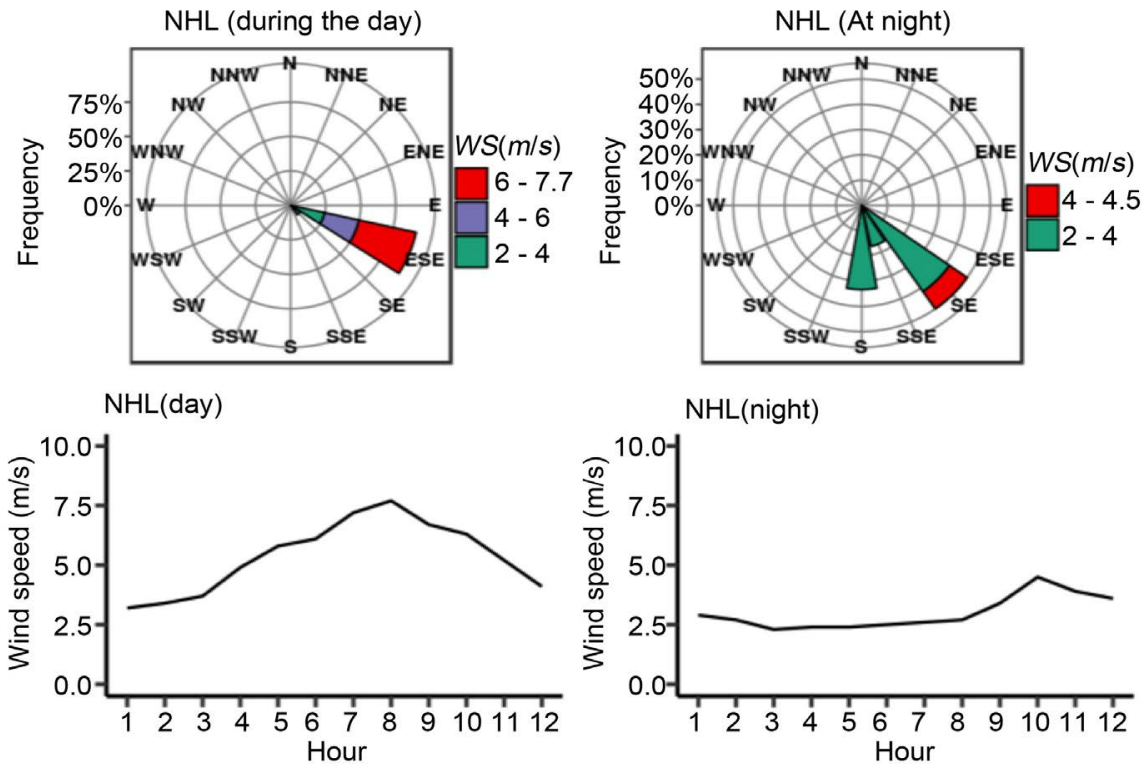

Figure 3. Average wind speed and wind direction at NHL over the period 1980-2016. 
Figure 4 presents the diurnal and nocturnal wind speed and wind direction at NIP. During the day, the wind rose points ESE and SE with the same frequency of $50 \%$. The analysis shows that $50 \%$ of the ESE winds blow with speeds between 4 to $6 \mathrm{~m} \cdot \mathrm{s}^{-1}$, while other $50 \%$ with speeds below $4 \mathrm{~m} \cdot \mathrm{s}^{-1}$. On the other hand, $70 \%$ of SE winds have speeds between 6 and $7.6 \mathrm{~m} \cdot \mathrm{s}^{-1}$ while $30 \%$ of SE winds blow with speeds below $6 \mathrm{~m} \cdot \mathrm{s}^{-1}$. Furthermore, the feature (NIP (day)) shows the highest wind speed at 8 and the lowest value at 1 . At night, the wind direction is SE where $90 \%$ of the winds blow with speeds below $4 \mathrm{~m} \cdot \mathrm{s}^{-1}$ while $10 \%$ of the winds have speeds between 4 and $4.4 \mathrm{~m} \cdot \mathrm{s}^{-1}$. The feature (NIP (night)) reveals the highest wind speed of the night at 10 (or 4:00 AM) with $4.4 \mathrm{~m} \cdot \mathrm{s}^{-1}$.

Figure 5 presents the daywise and nightwise average wind speed and wind direction at SHL. The diurnal wind rose points ESE, SE and SSE with a frequency of $41 \%$ for both ESE and SE winds while SSE winds blow with a frequency of $18 \%$. Furthermore, $62.5 \%$ of ESE winds blow with speeds below $4 \mathrm{~m} \cdot \mathrm{s}^{-1}$ while $37.5 \%$ blow with speeds between 4 and $6 \mathrm{~m} \cdot \mathrm{s}^{-1}$. Likewise, SE winds have all speeds between 6 and $7.7 \mathrm{~m} \cdot \mathrm{s}^{-1}$. The SSE winds move with speeds between 4 and $6 \mathrm{~m} \cdot \mathrm{s}^{-1}$ at SHL during the day. Moreover, the feature (SHL(day)) shows that the highest wind speed is observed at $8(2: 00 \mathrm{PM})$ while the lowest value is at 1 (7:00 $\mathrm{AM})$. On the other hand, the nocturnal wind rose points SE, SSE and S with a frequency of $18 \%, 55 \%$ and $27 \%$, respectively. Only $9 \%$ of the SSE winds have the speeds between 4 and $4.7 \mathrm{~m} \cdot \mathrm{s}^{-1}$ while the rest of the nocturnal winds blow with speeds below $4 \mathrm{~m} \cdot \mathrm{s}^{-1}$.

In the same way, Figure 6 shows the diurnal and nocturnal average wind speed and wind direction at SIP over the period 1980-2016. The diurnal wind rose point SE, SSE and S as wind directions with a frequency of $41 \%, 33 \%$ and $26 \%$, respectively. In fact, the analysis shows that $39 \%$ of SE winds blow with
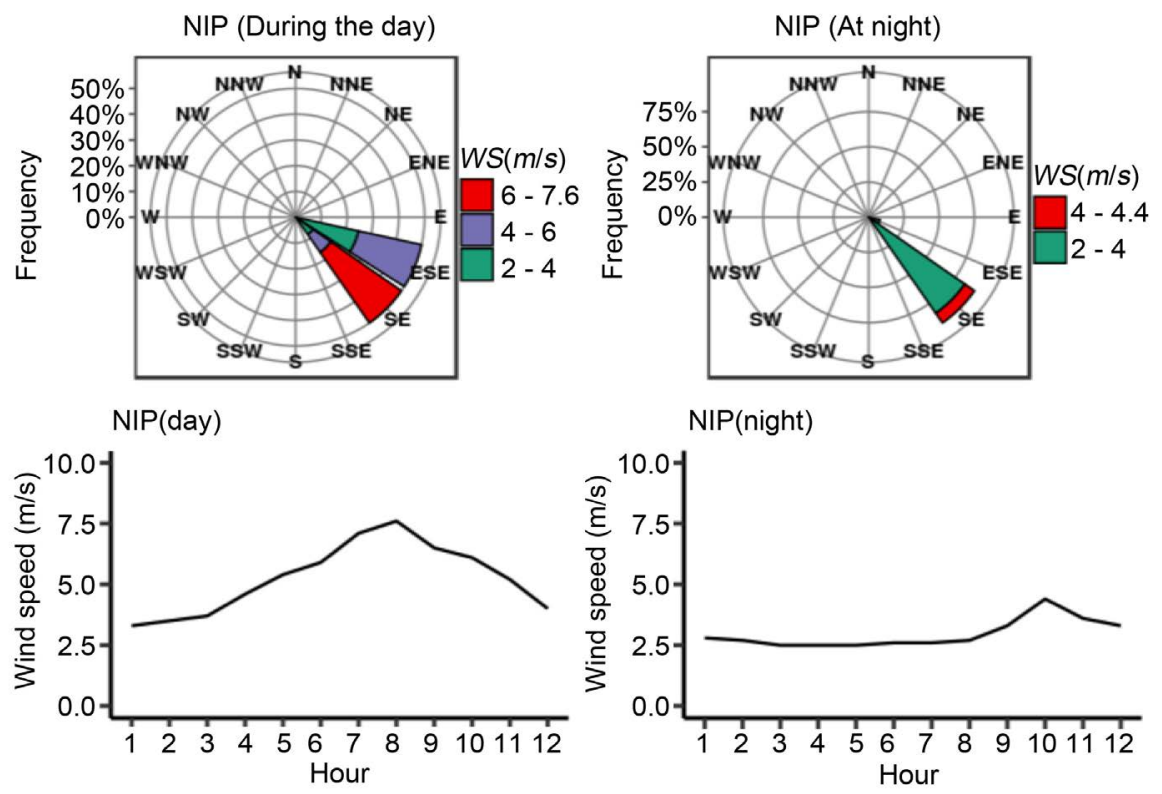

Figure 4. Average wind speed and wind direction at NIP over the period 1980-2016. 

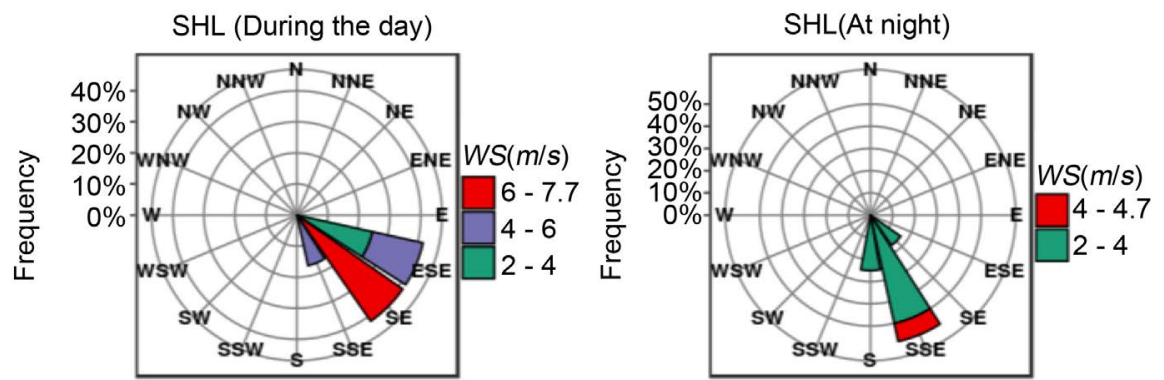

SHL(day)
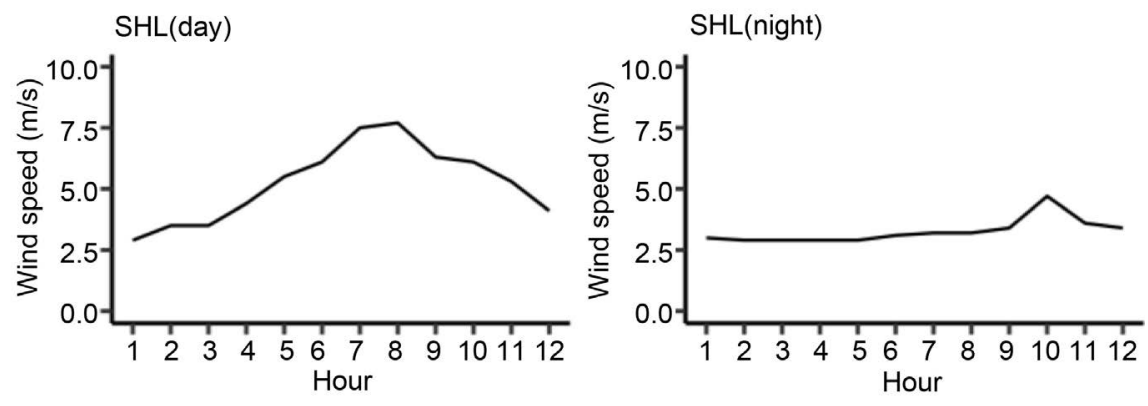

Figure 5. Average wind speed and wind direction at SHL over the period 1980-2016.
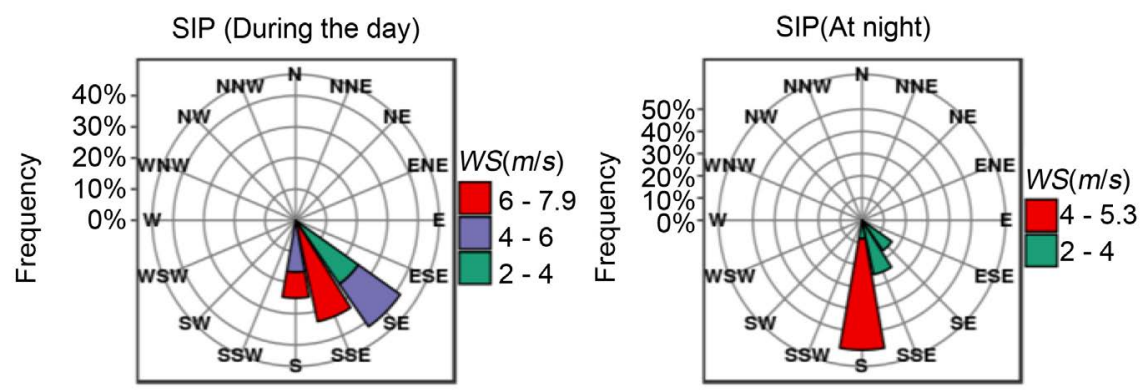

SIP(day)

SIP(night)
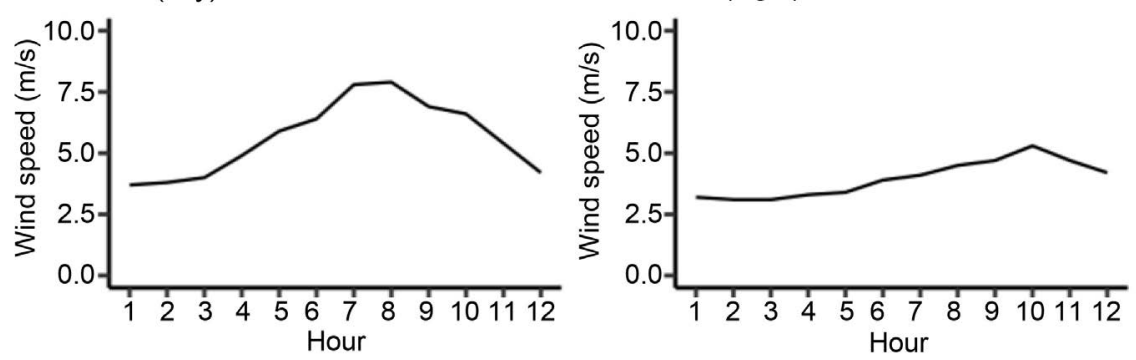

Figure 6. Average wind speed and wind direction at SIP over the period 1980-2016.

speeds between 4 and $6 \mathrm{~m} \cdot \mathrm{s}^{-1}$ while $61 \%$ blow with speeds below $4 \mathrm{~m} \cdot \mathrm{s}^{-1}$. Furthermore, all SSE winds move with speeds between 6 and $7.9 \mathrm{~m} \cdot \mathrm{s}^{-1}$ while $28 \%$ and $72 \%$ of $S$ winds blow with speeds between 6 and $7.9 \mathrm{~m} \cdot \mathrm{s}^{-1}$, and between 4 and $6 \mathrm{~m} \cdot \mathrm{s}^{-1}$, respectively. Moreover, the feature (SIP(day)) shows that the highest wind speeds are observed at $7(1: 00 \mathrm{PM})$ and $8(2: 00 \mathrm{PM})$ while the lowest are at 1 (7:00 AM). On the other hand, the nocturnal wind rose provides SE, SSE and S as wind directions with a frequency of $19 \%, 25 \%$ and $56 \%$, respectively. The SE and SSE winds blow with speeds below $4 \mathrm{~m} \cdot \mathrm{s}^{-1}$ while $\mathrm{S}$ winds move with speeds between 4 and $5.3 \mathrm{~m} \cdot \mathrm{s}^{-1}$. Indeed, the feature (SIP (night)) shows increase in wind 
speed from 6 to 10 where the highest wind speed is pointed at 10 (or 4:00 AM).

Overall, from the Figures 3-6, the findings revealed that at NHL, NIP, SHL and SIP, the average wind direction is between ESE and S. The highest wind speeds are observed in the afternoon before 4:00 PM, while at night the highest wind speeds are observed around 4:00 AM.

\subsubsection{Seasonal Variation of Site Characteristic}

Figure 7 presents the monthwise site characteristic including WS, SD, TI and AD at NHL, NIP, SHL and SIP over the historical period 1980-2016. SIP shows the highest seasonal WS. Furthermore, from May (5) to September (9), all the four sites present the highest WS of the year. This period coincides with the dry season in Burundi. During this season, hydropower plants experience the decrease of the water level in the reservoir which resulted in a difficult hydropower rationing. The figure also shows that the SD has high values during the rainy season between February and May, and in September and October while the lowest SD are observed in the dry seasons. The turbulence intensity (TI) is high (greater than 0.25) at NHL and NIP in March, April and October. All of the four sites reveal low TI values during the long dry season. Indeed, SIP does not reveal any month with high TI value, while only one month (October) of high TI is observed at SHL. In fact, low wind turbulence favors wind power generation while high wind turbulence may decrease it. Furthermore, the air density (AD) is higher at NIP and SIP than NHL and SHL. Indeed, this difference in AD is explained by the altitude between lowlands (NIP and SIP) and highlands (NHL
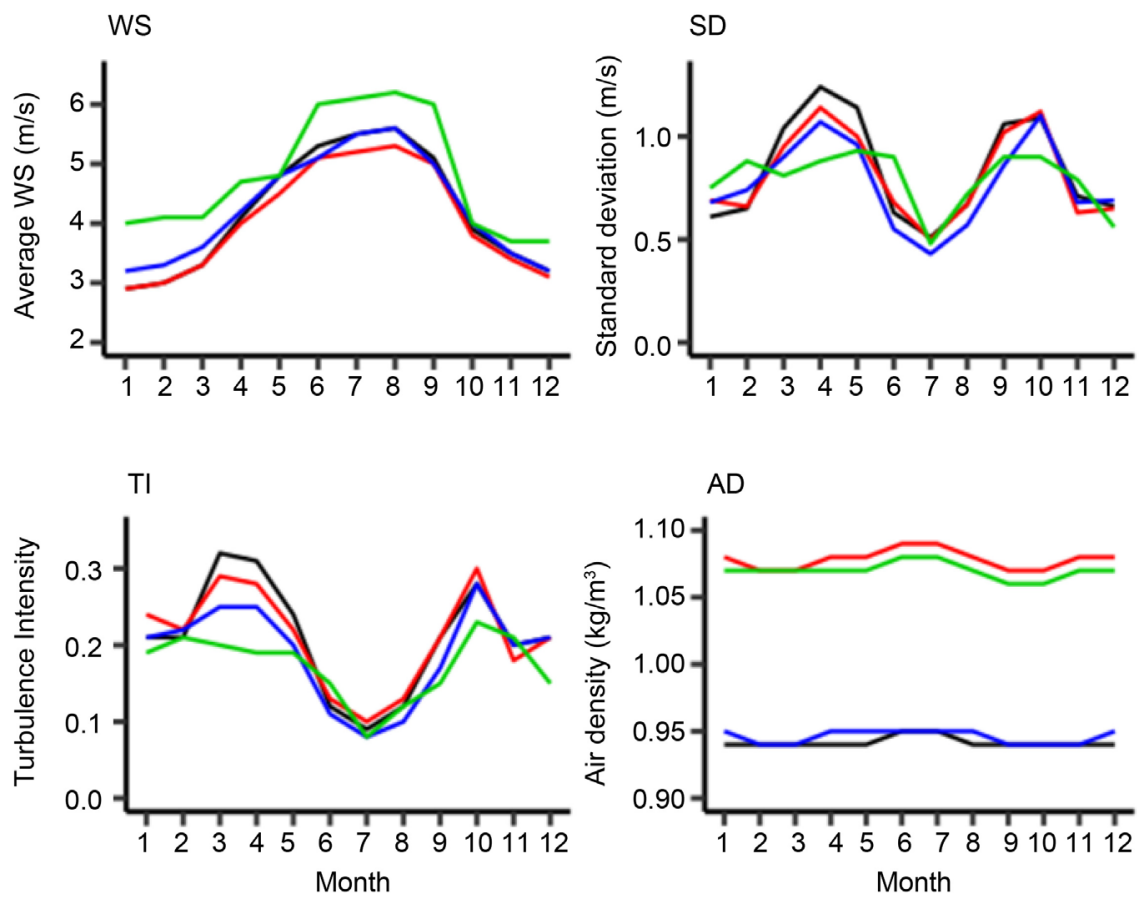

$$
\text { - NHL }-\mathrm{NIP}-\mathrm{SHL}-\mathrm{SIP}
$$

Figure 7. Monthly variation of average WS, SD, TI and AD at NHL, NIP, SHL and SIP. 
and SHL). Air temperature and Pressure are higher across lowlands than highlands. In fact, low $\mathrm{AD}$ values decrease the wind power potential while higher values favor it. The feature also shows a slight increase in $\mathrm{AD}$ during the dry season all over the four sites.

\subsubsection{Spatial Distribution of Monthly Wind Speed}

Figure 8 presents monthwise wind speed from January to December at NHL, NIP, SHL and SIP over the period 1980-2016. In fact, from January to December, WS are higher in the south (SIP and SHL) than the north (NIP and NHL). The analysis shows that areas nearby the Lake Tanganyika (the south of NIP, SIP and the south-west of SHL) have higher WS than other parts. Furthermore, the year cycle can be divided into two main parts including October to April where WS are below $4.5 \mathrm{~m} \cdot \mathrm{s}^{-1}$ and from May to September where WS are higher than $4.5 \mathrm{~m} \cdot \mathrm{s}^{-1}$. Indeed, the findings revealed that the month of August has the highest WS of the year above $5.5 \mathrm{~m} \cdot \mathrm{s}^{-1}$.

\subsubsection{Wind Speed Interannual Variability}

Figure 9 presents the WS interannual variability at NHL, NIP, SHL and SIP over the period 1980-2016. The analysis of the standardized WS index reveals two main parts over the four sites including the period 1980-1996 in low wind speeds and the period 1997-2016 in high wind speeds. Indeed, Lawin et al. [15] attributed the cause of the difference between the two periods on environmental destruction. Furthermore, Havyarimana [42] showed negative impact of socio-political instability which started in Burundi in 1993 on the environment. His findings highlighted an increase in natural vegetation disturbance by anthropogenic activities over time.

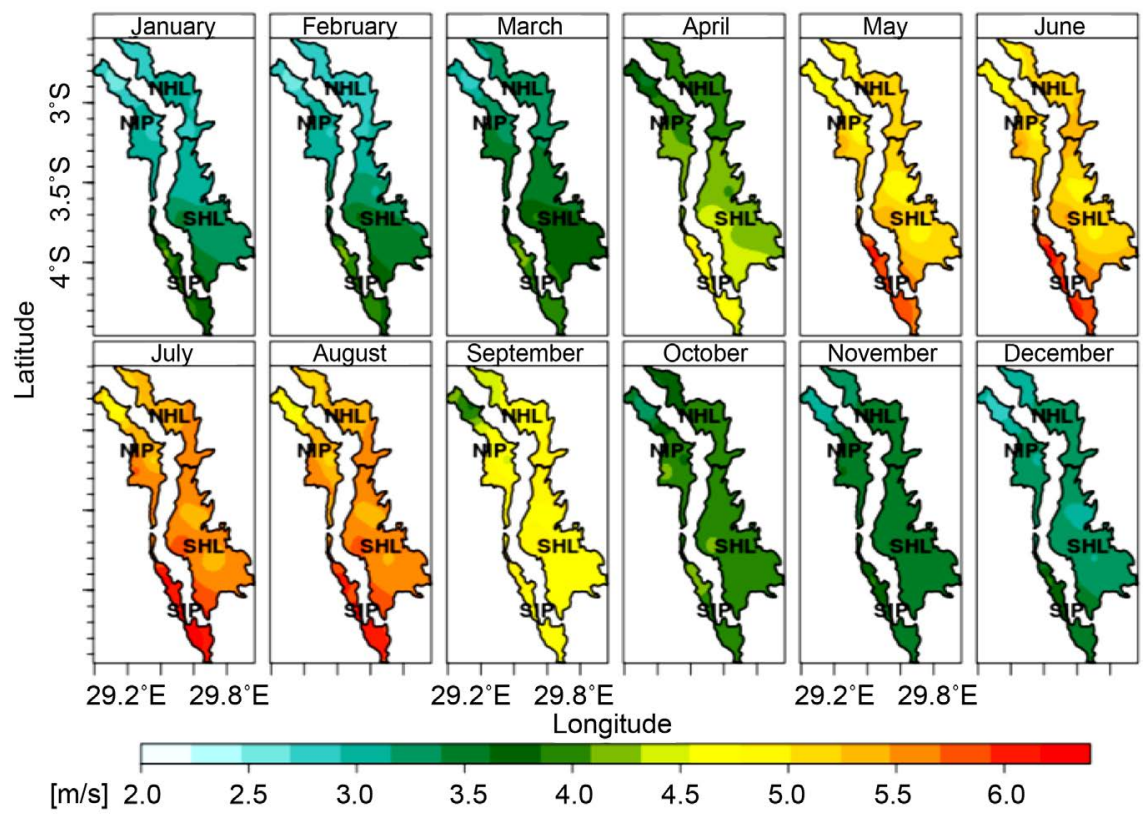

Figure 8. Monthly spatial variation of average WS at NHL, NIP, SHL and SIP over the period 1980-2016. 

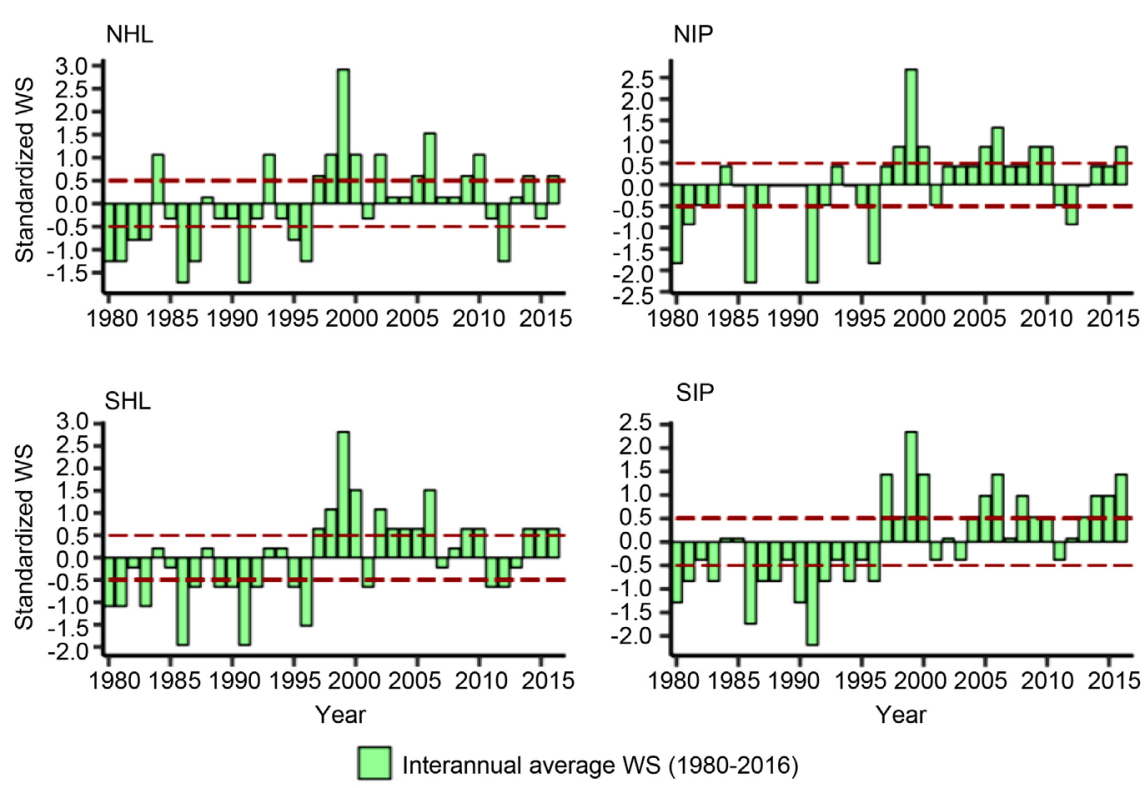

Figure 9. Standardized WS index at NHL, NIP, SHL and SIP over the period 1980-2016.

Over the period 1980-1996, a further analysis of Figure 9 revealed 9 years and 5 years of low WS at NHL and NIP, respectively, while 11 years of low WS were pointed out at SHL and SIP. The findings show that only NHL has 2 years of high WS over that period. Moreover, the period 1997-2016 presented 11 years, 8 years, 14 years and 9 years of high WS at NHL, NIP, SHL and SIP, respectively. Likewise, over the same period, NHL and NIP have 1 year of low WS, and SHL has 3 years, while SIP has no low WS over the period 1997-2016. Overall, the increase in years of high WS may have positive implication on wind power production, and hence reduce the electrical gap observed during the long dry season. Indeed, MK's test detected an upward trend in WS over the period 1980-2016 at NHL, NIP, SHL and SIP. In fact, at significance level equals to 0.05, the Kendall's tau of $0.31,0.38,0.36$ and 0.49 with their respective p-values equal to $0.0098,0.0016,0.0033$ and $<0.0001$ were revealed at NHL, NIP, SHL and SIP, respectively. This increasing trend in wind speed is consistent with the findings in many studies from the East Africa [15] [43].

\subsubsection{Wind Power Density over the Baseline Period}

Figure 10 presents the monthly distribution of wind power density (WPD) over the reference period 1981-2010. The figure highlights areas in low and high WPD for the twelve months of the year. Therefore, from June to September, we have months in high WPD with values greater than $60 \mathrm{~W} \cdot \mathrm{m}^{-2}$ while from November to March, we have months in low WPD with values less than $25 \mathrm{~W} \cdot \mathrm{m}^{-2}$. The findings show that the months of April, May and October have WPD between 25 and $60 \mathrm{~W} \cdot \mathrm{m}^{-2}$. Furthermore, within the four sites, SIP is revealed to have higher WPD than other sites over the entire baseline period with values greater than $120 \mathrm{~W} \cdot \mathrm{m}^{-2}$ during the summer time. Indeed, from the results, the four sites are only promising for installing wind turbine for small-scale power 


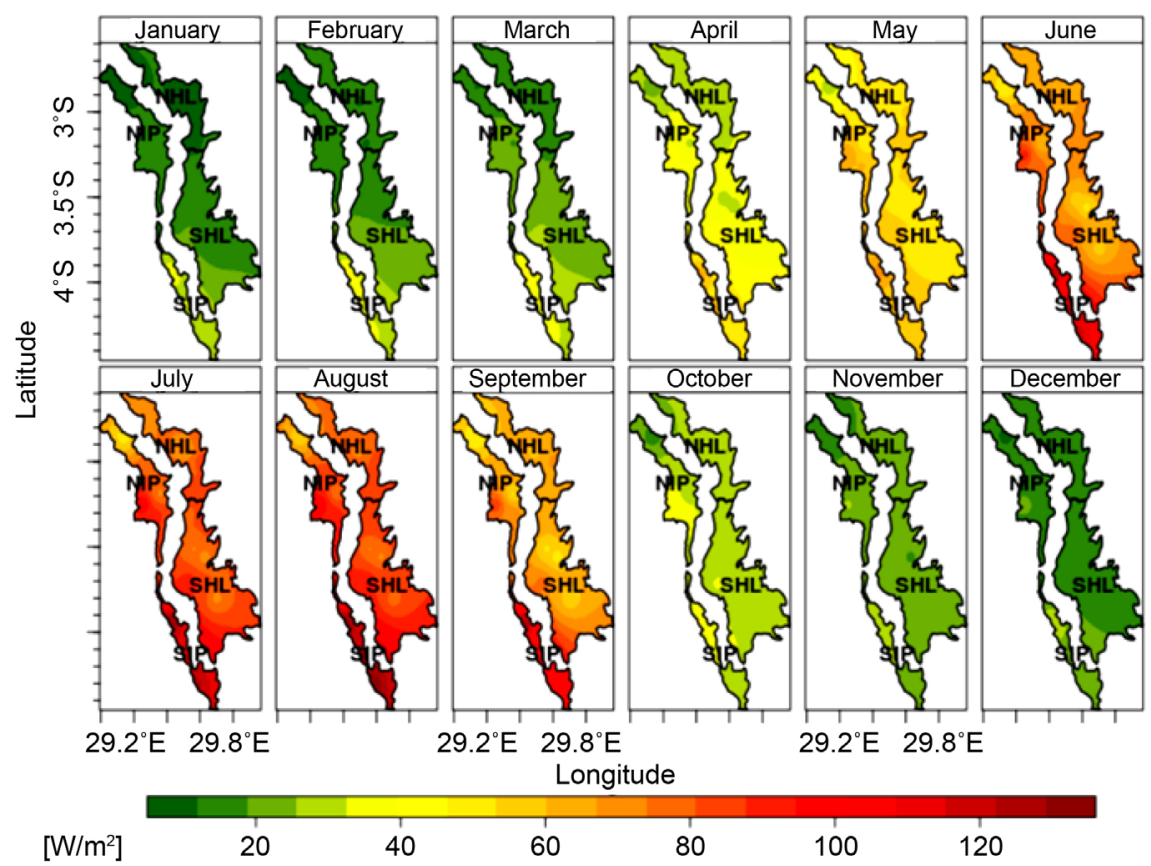

Figure 10. Spatial distribution of average WPD at NHL, NIP, SHL and SIP over the period 1981-2010.

generation. Otherwise, large-scale wind power generation require that mean wind speeds exceed $7 \mathrm{~m} \cdot \mathrm{s}^{-1}$ to generate at least $200 \mathrm{~W} \cdot \mathrm{m}^{-2}[24]$.

According to the ISTEEBU report [44], Burundi hydroelectricity production is characterized by a lot of fluctuation due to its dependence on rainfall; which impels the importation of hydroelectricity and the usage of fossil fuel for electricity generation especially during the dry season. For example, in 2007, the report shows that $39 \%$ of electricity was imported from RUZIZI I and RUZIZI II of the Democratic Republic of the Congo. In 2013, Burundi started its three electricity generators using fossil fuel to generate 14\% (23 MW) of national electricity production. The usage of the power generators reduced importation to $37 \%$. However, the cost of $1 \mathrm{kWh}$ for consumers was increased up to $47 \% \mathrm{com}$ pared to the cost of 2007. Therefore, wind power can contribute to reduce electricity importation and the usage of fossil fuel for electricity generation. Moreover, the demand of water for irrigation is seasonal and it is found that the highest wind power density coincides with the dry season which may favor wind powered water pumping applications.

\subsection{Future Wind Power Potential}

We recall that the future climate has been spatially and temporally analyzed using a multi-model ensemble of eight Regional Climate Models (CCCma, CNRM, ICHEC, IPSL, MIROC, MPI, NCC and NOAA) over the periods 2019-2040 and 2071-2100 according to the reference period 1981-2010. Specifically, a multi-model mean has been computed and adopted for each emission scenario (RCP 4.5 and RCP 8.5). 


\subsubsection{Projected Wind Speed over the Period 2019-2040}

Figure 11 and Figure 12 present the spatial projected monthly WS following RCP 4.5 and RCP 8.5 , respectively over the period 2019-2040 according to the baseline period 1981-2010. The analysis of Figure 11 shows that from October to March, projected WS are between 3 and $5 \mathrm{~m} \cdot \mathrm{s}^{-1}$ all over the study area. Indeed, the months April-September are expected to experience WS above $5 \mathrm{~m} \cdot \mathrm{s}^{-1}$. The months June-August are forecasted to have the highest WS above $6.5 \mathrm{~m} \cdot \mathrm{s}^{-1}$. Among the four sites, SIP is expected to experience the highest WS. Furthermore, the south of NIP will experience higher WS than other parts of NIP. Moreover, the southern parts of SHL are projected to be in higher WS than other parts of SHL. Likewise, the analysis of Figure 12 reveals that from October to April, the WS are projected to be between 3.5 and $5.2 \mathrm{~m} \cdot \mathrm{s}^{-1}$ where the month of April and March (the south) will experience WS between 4.5 and $5.2 \mathrm{~m} \cdot \mathrm{s}^{-1}$. Furthermore, the months May-September are forecasted to experience WS between 6 and $8 \mathrm{~m} \cdot \mathrm{s}^{-1}$. Higher WS are projected at SIP than other parts over the period 2019-2040 following RCP 8.5. Comparing findings from RCP 4.5 with RCP 8.5, WS values are higher in RCP 8.5 with a slight difference except at SIP in September.

\subsubsection{Projected Wind Speed over the Period 2071-2100}

Figure 13 and Figure 14 present the spatial forecasted monthly WS following respectively RCP 4.5 and RCP 8.5 over the period 2071-2100 according to the reference period 1981-2010. The analysis of Figure 13 shows that the highest WS of the year cycle are expected in May-September with values between 6.5 and $8.5 \mathrm{~m} \cdot \mathrm{s}^{-1}$ while the lowest WS are projected in October-April with values between 4.5 and $6.5 \mathrm{~m} \cdot \mathrm{s}^{-1}$. Furthermore, SIP is forecasted to have higher WS

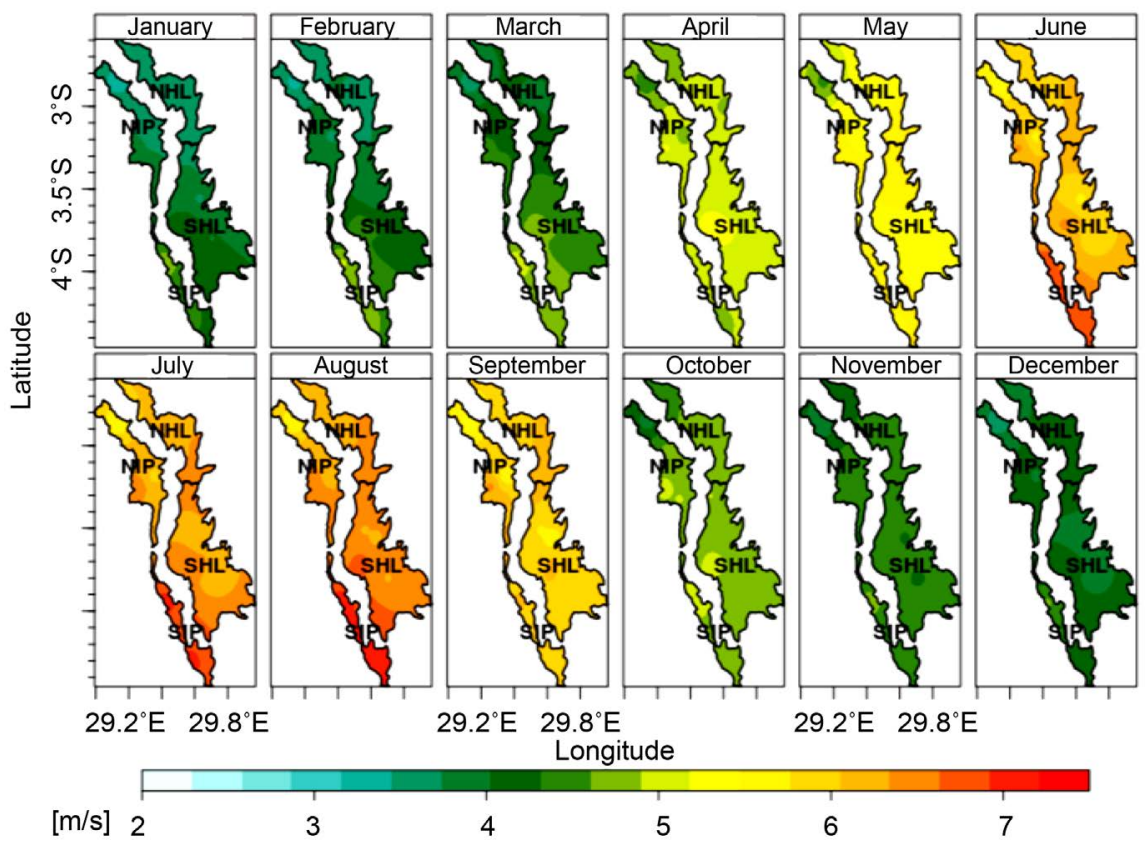

Figure 11. Monthly projected average WS at NHL, NIP, SHL and SIP following RCP 4.5. 


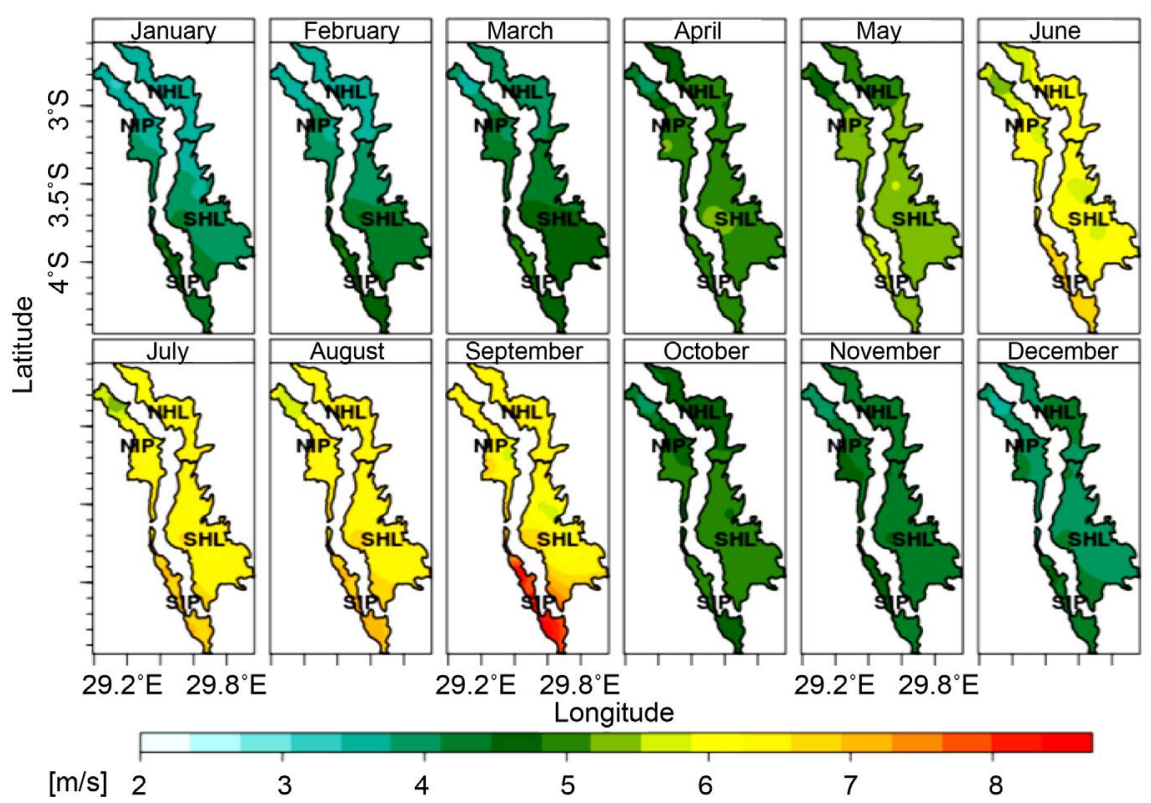

Figure 12. Monthly projected average WS at NHL, NIP, SHL and SIP following RCP 8.5.

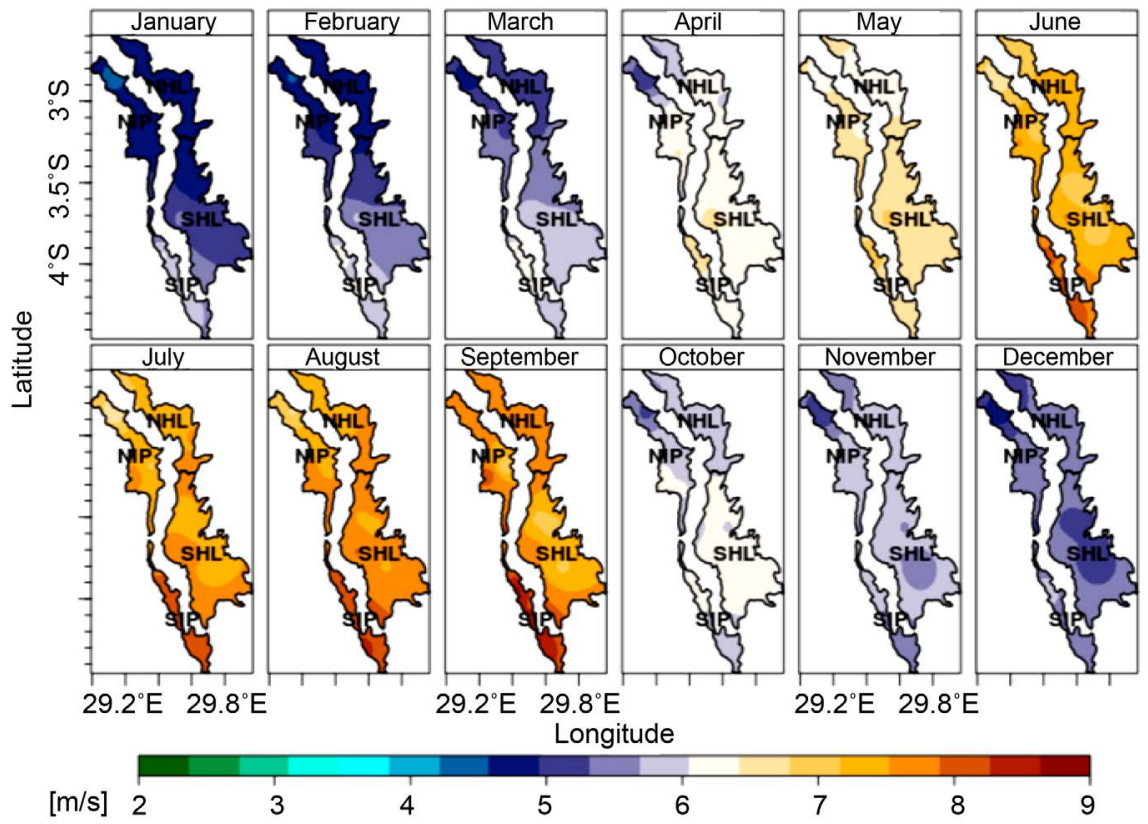

Figure 13. Monthly projected average WS at NHL, NIP, SHL and SIP following RCP 4.5.

than other parts from January to December. The south of NIP and the South-West of SHL will experience higher WS than other parts of NIP and SHL, respectively.

The analysis of Figure 14 reveals that from October to April, the WS are projected to vary between 4.8 and $6.5 \mathrm{~m} \cdot \mathrm{s}^{-1}$ while the months May-September are projected to experience WS between 6.5 and $10 \mathrm{~m} \cdot \mathrm{s}^{-1}$. Higher WS are projected at SIP than other parts of the study area. Comparing the findings from RCP 4.5 with RCP 8.5 over the period 2071-2100, WS values are higher in RCP 


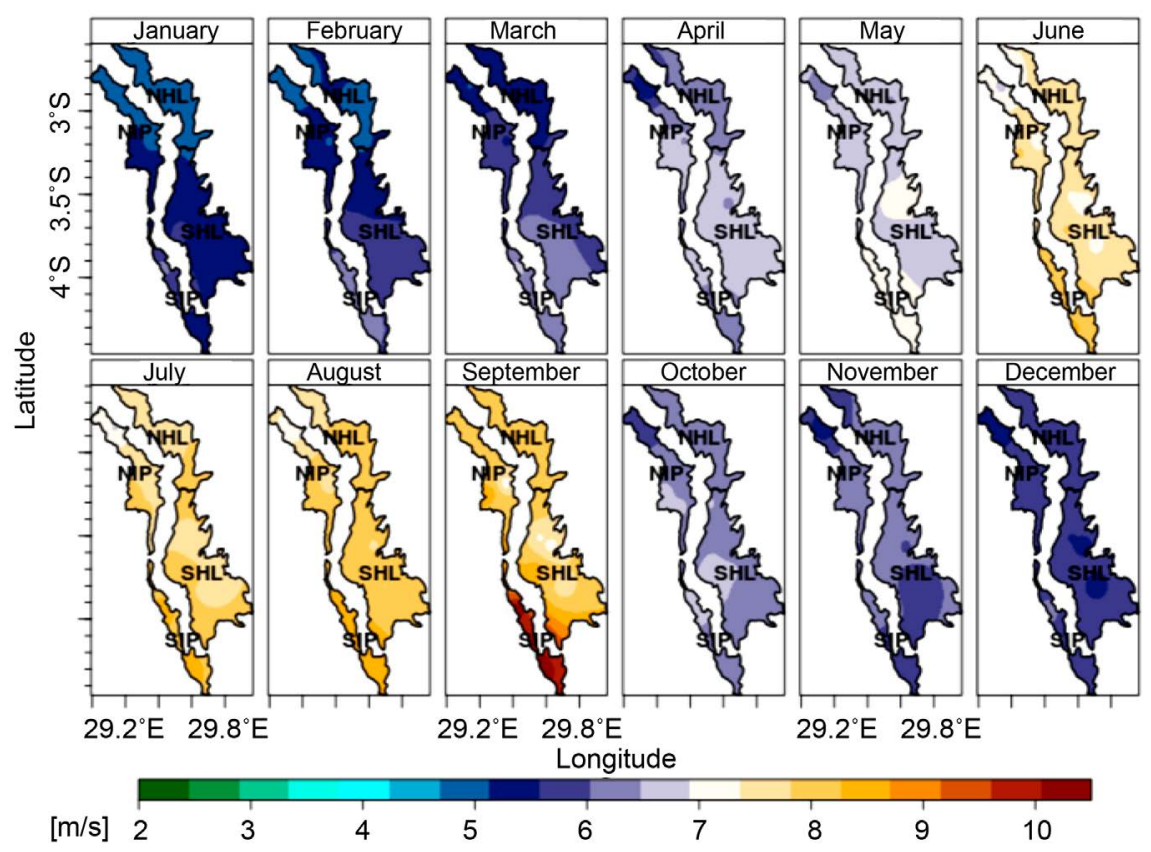

Figure 14. Monthly projected average WS at NHL, NIP, SHL and SIP following 8.5.

8.5 with a slight difference except at SIP in September.

Overall, comparing the projection over the period 2019-2040 with the projections over the period 2071-2100 according to the baseline period 1981-2010, the findings show that projected WS are higher over the far future than near future. Indeed, higher projected wind speeds will obviously have positive impact on wind power production.

\subsubsection{Interannual Projected Wind Speed}

Figure 15 presents interannual projected WS over the period 2019-2040 following RCP 4.5 (RCP 4.5 (a) and RCP 8.5 (a)), and over the period 2071-2100 following RCP 4.5 (RCP 4.5 (b) and RCP 8.5 (b)) with their reference period 1981-2010 (obs). The figure shows that future interannual WS will be characterized by a lot of fluctuations and a general increase in WS. Furthermore, the features show that WS values projected under RCP 4.5 and RCP 8.5 are very close all over the four sites. The analysis revealed that over the period 2019-2040, both scenarios projected an average increase in interannual WS of 0.9 and 0.8 $\mathrm{m} \cdot \mathrm{s}^{-1}$ in the highlands and lowlands, respectively.

Likewise, over the period 2071-2100, an average increase of 2.1 and $2 \mathrm{~m} \cdot \mathrm{s}^{-1}$ is respectively expected across the highlands and lowlands in RCP 4.5 while in RCP 8.5, an average increase of 2.4 and $2.3 \mathrm{~m} \cdot \mathrm{s}^{-1}$ are projected in the latter respective sites. However, in both climate scenarios, all interannual average wind speeds will hover between 4 and $8 \mathrm{~m} \cdot \mathrm{s}^{-1}$. Indeed, over the period 2071-2100, projected WS are expected to be slightly higher in RCP 8.5 than RCP 4.5. Overall, the findings obviously shows that projected wind power are expected to increase. These findings are consistent to other studies all over the world [2] [4] [43] [45]. 

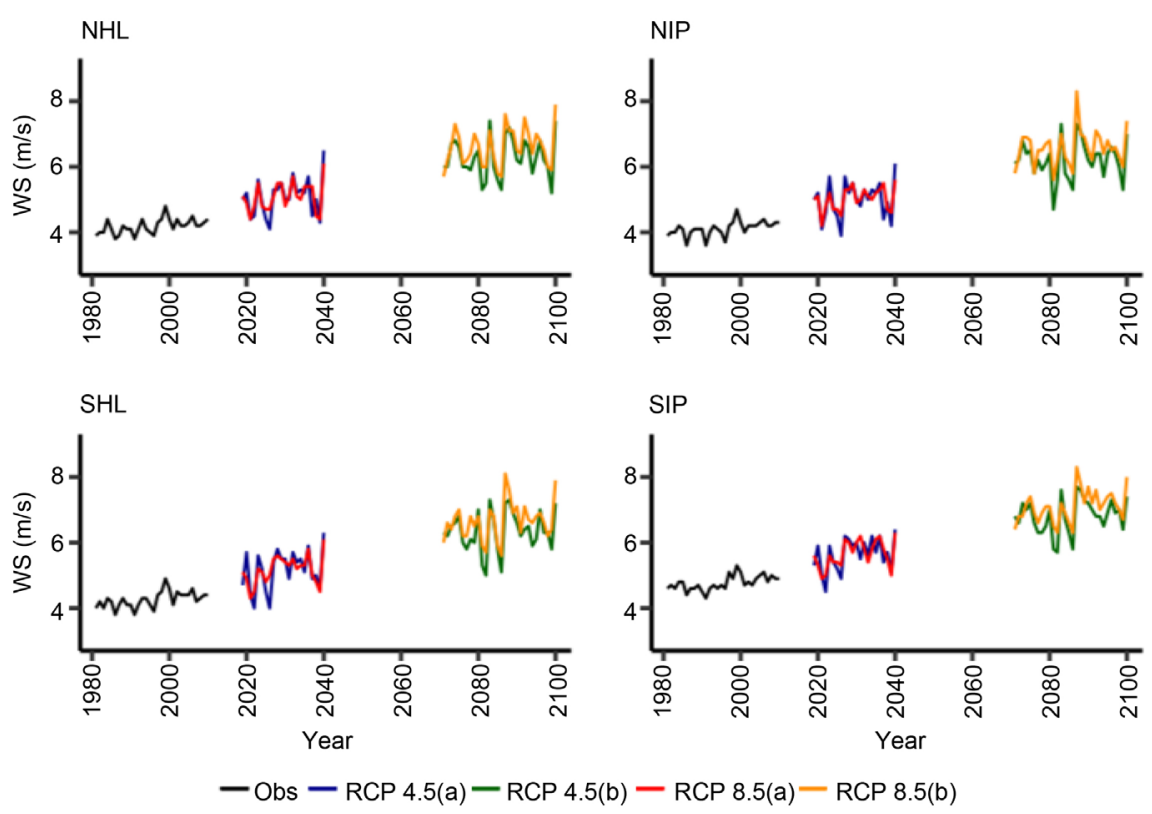

Figure 15. Observed and interannual projected average WS at NHL, NIP, SHL and SIP.

\subsubsection{Wind Power Density Projected Changes}

Figure 16 and Figure 17 show monthwise and annual projected changes in WPD over the periods 2019-2040 and 2071-2100 at NHL, NIP, SHL and SIP according to the baseline period 1981-2010. The figures used violins to illustrate WPD projected changes. The red dot shows the mean of projected WPD changes. The thicker part indicates that the monthly WPD change value in that section of the violin has higher frequency, and the thinner part implies lower frequency. The bottom of the violin shows the minimum WPD change value while the top of the violin means the maximum value. For more clarity, only months corresponding to the maximum and minimum changes have been plotted with the violin. Furthermore, the first crossbar of the violin marks the $1^{\text {st }}$ quartile, the second crossbar is the $2^{\text {nd }}$ quartile (median) and the last is the $3^{\text {rd }}$ quartile.

Therefore, over the period 2019-2040 following RCP 4.5, an average WPD change of $28.04 \mathrm{~W} \cdot \mathrm{m}^{-2}, 30.27 \mathrm{~W} \cdot \mathrm{m}^{-2}, 28.15 \mathrm{~W} \cdot \mathrm{m}^{-2}$ and $31.1 \mathrm{~W} \cdot \mathrm{m}^{-2}$ is projected at NHL, NIP, SHL and SIP, respectively. Although these changes are close, the analysis shows that WPD changes in quartiles for lowlands (NIP and SIP) are higher than highlands (NHL and SHL). All over the four sites, the month of August is projected to experience the highest WPD changes while January will have the lowest. In August the highest WPD change value is expected at SIP with $50.6 \mathrm{~W} \cdot \mathrm{m}^{-2}$, while in January the lowest change will be at NHL with $12.5 \mathrm{~W} \cdot \mathrm{m}^{-2}$. Likewise, following RCP 8.5, the month of September is expected to have the highest WPD changes all over the study area. Indeed, in the lowlands, September shows the higher changes than highlands where SIP is expected to experience the highest WPD change value equal to $99.6 \mathrm{~W} \cdot \mathrm{m}^{-2}$. Overall, in RCP 8.5, NHL, NIP, SHL and SIP are projected to experience WPD changes equal to $28.3 \mathrm{~W} \cdot \mathrm{m}^{-2}$, 


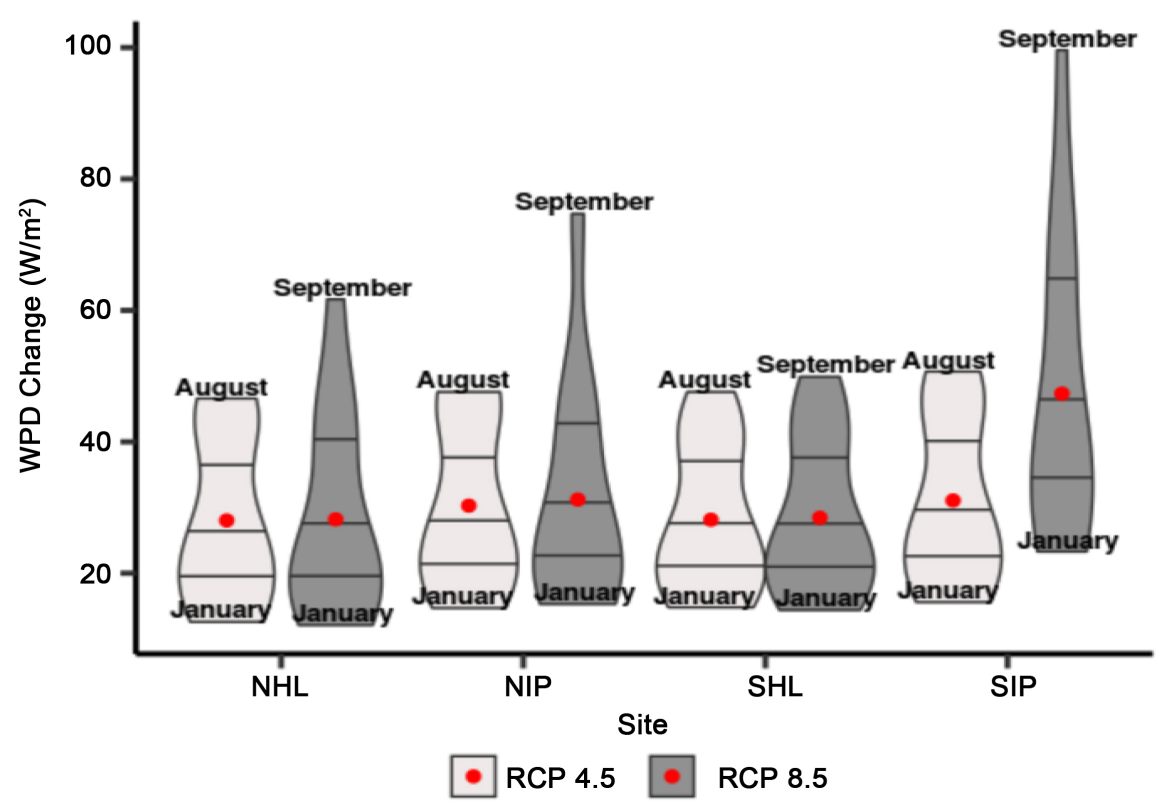

Figure 16. Projected monthly and annual average WPD changes over the period 2019-2040.

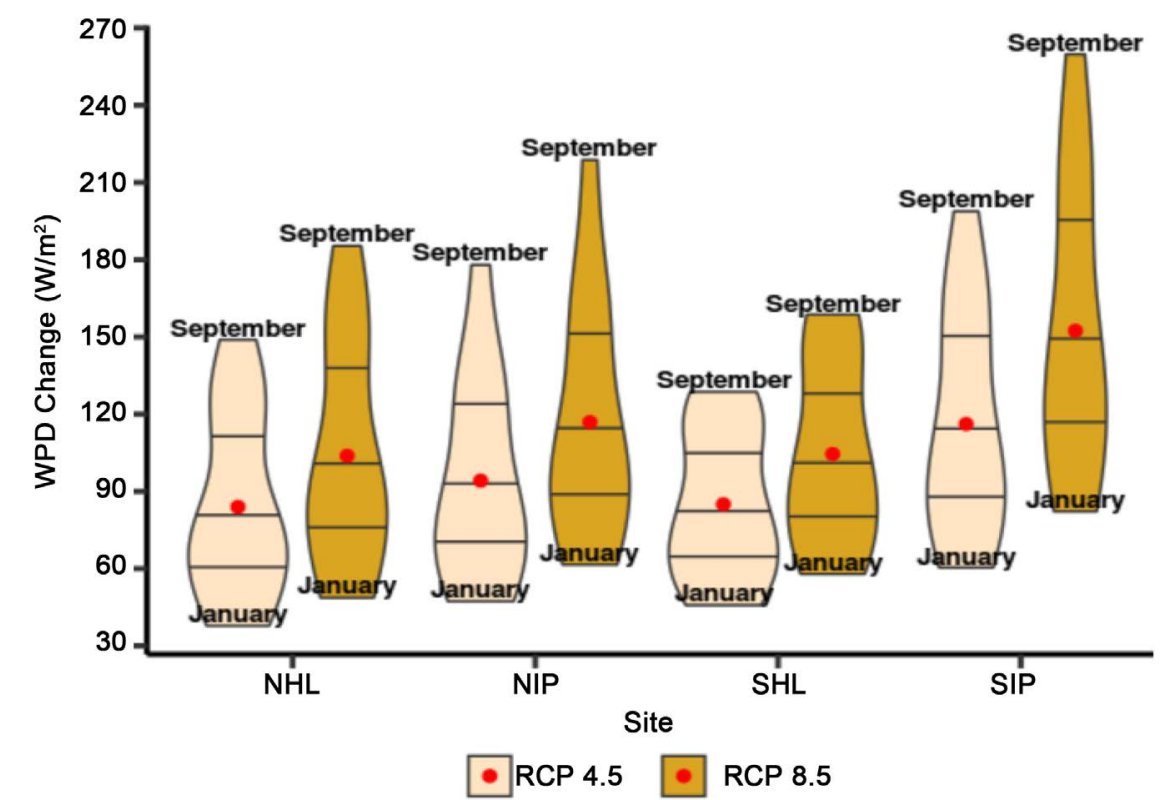

Figure 17. Projected monthly and annual average WPD changes over the period 2071-2100.

$31.24 \mathrm{~W} \cdot \mathrm{m}^{-2}, 28.42 \mathrm{~W} \cdot \mathrm{m}^{-2}$ and $47.35 \mathrm{~W} \cdot \mathrm{m}^{-2}$, respectively. Both the scenarios agree on January as a projected month to experience the lowest WPD changes across the lowlands and highlands.

On the other hand, over the period 2071-2100 (Figure 17) following RCP 4.5, averages WDP change equal to $83.96 \mathrm{~W} \cdot \mathrm{m}^{-2}, 94.17 \mathrm{~W} \cdot \mathrm{m}^{-2}, 85 \mathrm{~W} \cdot \mathrm{m}^{-2}$ and 116.16 $\mathrm{W} \cdot \mathrm{m}^{-2}$ are projected at NHL, NIP, SHL and SIP, respectively. The analysis shows that WPD changes in lowlands are higher than highlands. In addition, within the 
two regions (lowlands and highlands), changes are higher in the south than north. Indeed, all over the four sites, September is projected to experience the highest WPD changes while January will have the lowest. In January the lowest WPD change value is forecasted at NHL with $37.8 \mathrm{~W} \cdot \mathrm{m}^{-2}$, while in September the highest WPD change is expected at SIP with $198.8 \mathrm{~W} \cdot \mathrm{m}^{-2}$. In the same way, following RCP 8.5 over the same period, the month of September is expected to have the highest WPD changes for all the four sites. Indeed, September shows the highest WPD change equal to $259.8 \mathrm{~W} \cdot \mathrm{m}^{-2}$ at SIP while January projects the lowest WPD change equal to $48.7 \mathrm{~W} \cdot \mathrm{m}^{-2}$ at NHL.

Overall, NHL, NIP, SHL and SIP are expected to experience WPD changes equal to $103.82 \mathrm{~W} \cdot \mathrm{m}^{-2}, 116.9 \mathrm{~W} \cdot \mathrm{m}^{-2}, 104.51 \mathrm{~W} \cdot \mathrm{m}^{-2}$ and $152.39 \mathrm{~W} \cdot \mathrm{m}^{-2}$, respectively. Comparing the findings from the two scenarios over the period 2071-2100, both agree on January and September as months projected to experience the lowest and the highest WPD changes, respectively throughout the lowlands and highlands.

Furthermore, comparing the period 2019-2040 with 2071-2100, both of them agree on the increase in the projected wind power density according to the reference period 1981-2010. In fact, no negative WPD change was found.

\subsubsection{Spatial Distribution of Wind Power Density Changes}

Figure 18 presents the spatial distribution of annual WPD changes over the period 2019-2040 (19/40) and over the period 2071-2100 (71/100) following RCP 4.5 and RCP 8.5 according to the reference period 1981-2010. The figure shows that changes are expected to be higher in RCP 8.5 than RCP 4.5 over both periods. In fact, changes in RCP 4.5 will be less than $50 \mathrm{~W} \cdot \mathrm{m}^{-2}$ while changes in RCP 8.5 will be higher than $75 \mathrm{~W} \cdot \mathrm{m}^{-2}$.

Moreover, the figure highlights that changes are projected to increase over the two time periods within each climate scenario. Furthermore, western areas nearby the Lake Tanganyika are expected to experience higher increase in WPD

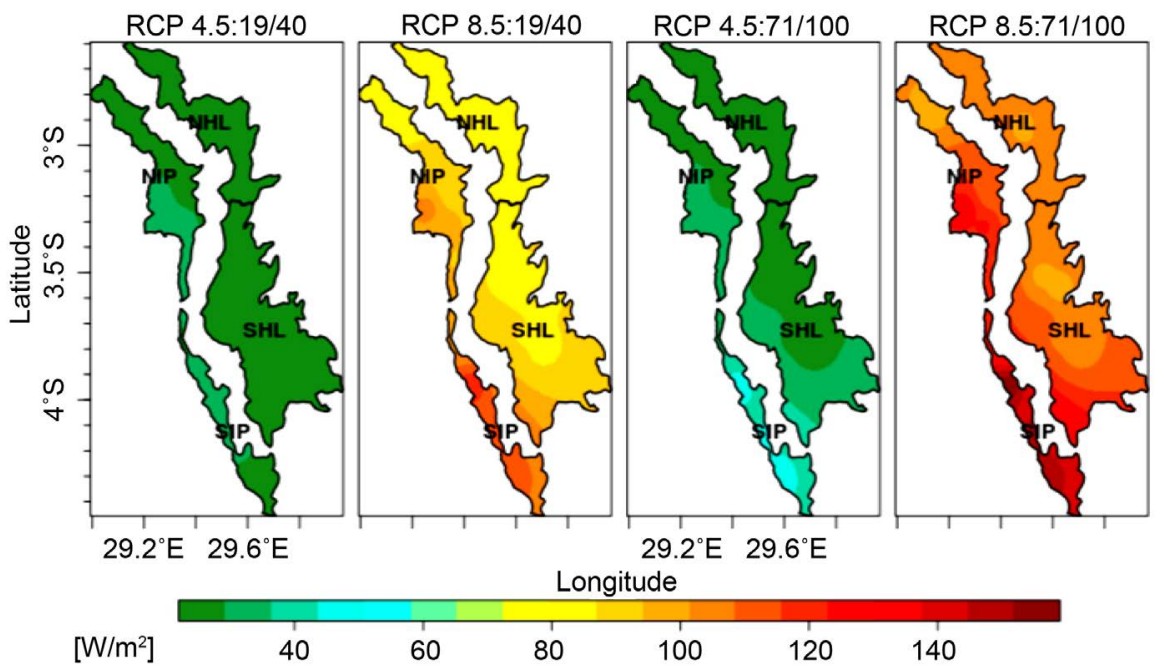

Figure 18. Annual spatial distribution of projected changes in wind power density. 
than other areas. Indeed, the entire SIP, the south of NIP, the south and the south-west of SHL are projected to experience higher changes in wind power density than other parts of the study area.

\subsubsection{Future Wind Speed Potential on Different Heights in the Surface Layer}

The axes of modern wind turbines are located at different heights in layer up to $165 \mathrm{~m}$ thick [35]. For most of them, the cut-in speed is $2.5-5 \mathrm{~m} \cdot \mathrm{s}^{-1}$, the rated speed is $10-15 \mathrm{~m} \cdot \mathrm{s}^{-1}$, the cut-out speed is within $24-25 \mathrm{~m} \cdot \mathrm{s}^{-1}$ [36]. Indeed, all these values refer to wind speed at the height of axis of the wind turbine. Recall that in surface layer, the wind speed increases with increasing height above the ground [24]. Therefore, it is necessary to take into consideration that the wind speed at hub height has higher values. Figures 19-21 show projected wind speed at $50 \mathrm{~m}, 100 \mathrm{~m}$ and $150 \mathrm{~m}$ heights. The analysis revealed that from $12 \mathrm{~m}$ to $50 \mathrm{~m}$ height, the lowest expected increase in wind speed over the four sites is $1.1 \mathrm{~m} \cdot \mathrm{s}^{-1}$, while the highest increase of $2.2 \mathrm{~m} \cdot \mathrm{s}^{-1}$ and $2.8 \mathrm{~m} \cdot \mathrm{s}^{-1}$ are projected at $150 \mathrm{~m}$ height for the four sites over the period 2019-2040 and 2071-2100, respectively under both RCP 4.5 and RCP 8.5. Overall, $150 \mathrm{~m}$ may be considered as the best height for wind power generation. This can help to reduce electricity importation and the fossil fuel dependence to generate electricity and the cost of $1 \mathrm{kWh}$ especially during the dry season.

The findings from this study projecting increase in WS which implies increase in WPD are consistent with many studies from different regions of the globe as well as studies from East Africa [2] [45] [46] [47] [48]. Indeed, Lawin et al. [15] reported increasing trend in wind speed at Northern Imbo plain while Collins et al. [14], predicted that Burundi would experience more extreme weather conditions in the future characterized by high winds; which is consistent with our findings.

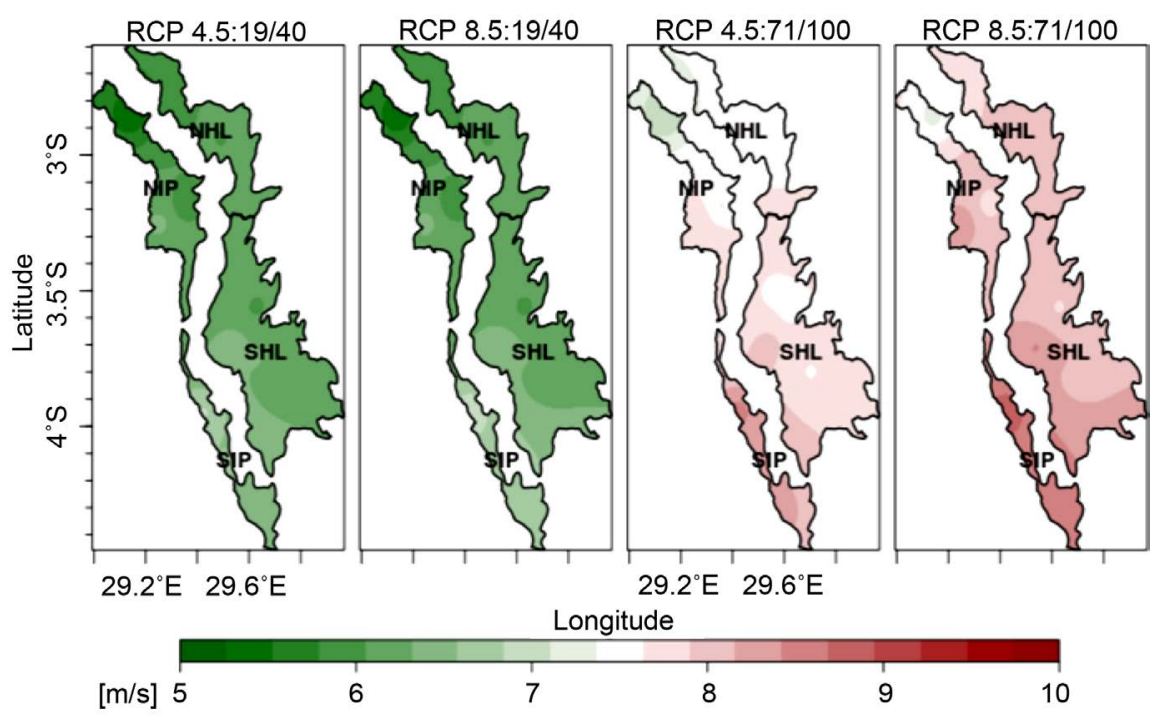

Figure 19. Spatial distribution of projected annual wind potential at $50 \mathrm{~m}$. 


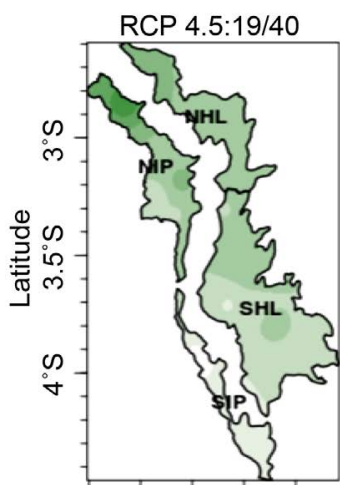

$29.2^{\circ} \mathrm{E} \quad 29.6^{\circ} \mathrm{E}$
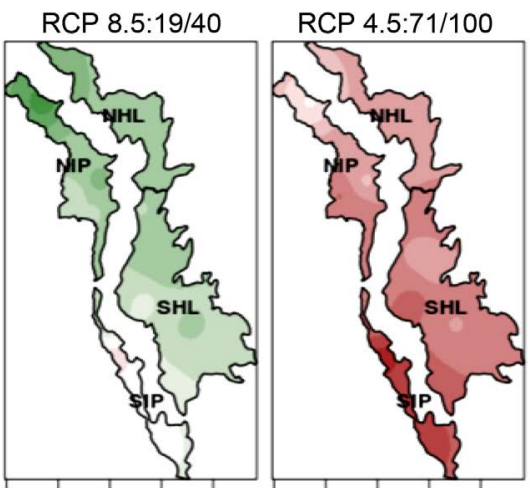

$29.2^{\circ} \mathrm{E} 29.6^{\circ} \mathrm{E}$

Longitude

$[\mathrm{m} / \mathrm{s}] 5$

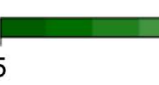

6

7

8

RCP 8.5:71/100

Figure 20. Spatial distribution of projected annual wind potential at $100 \mathrm{~m}$.

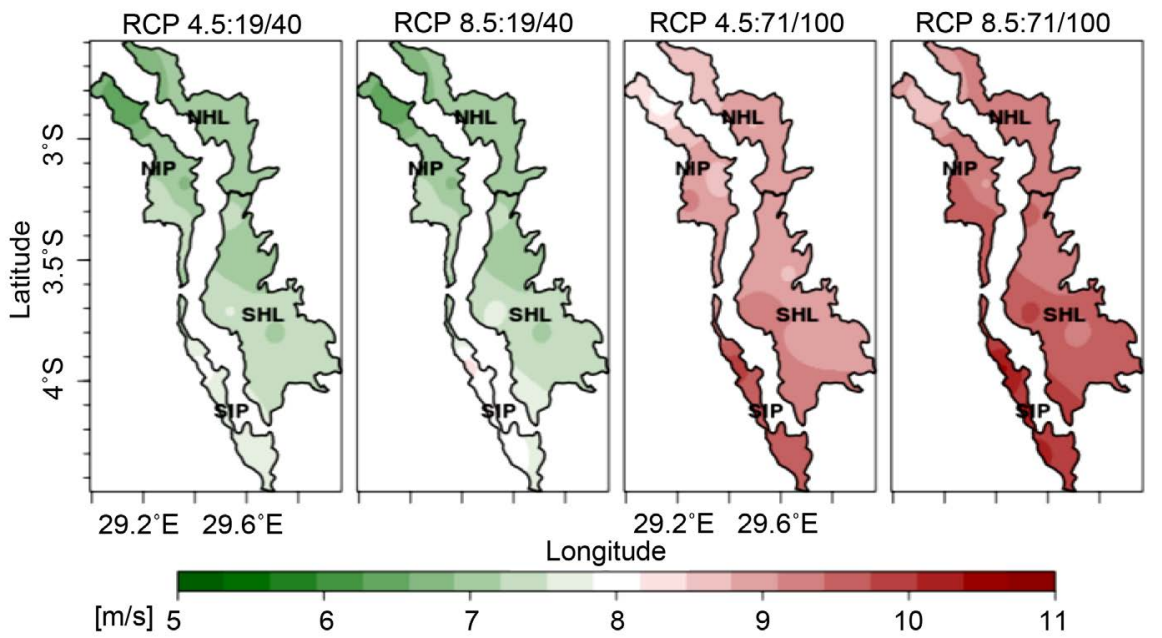

Figure 21. Spatial distribution of projected annual wind potential at $150 \mathrm{~m}$.

\section{Conclusions}

This study analyzed the impact of climate change on wind power potential over the periods 2019-2040 and 2071-2100 using two emission scenarios RCP 4.5 and RCP 8.5 according to the reference period 1981-2010.

The wind over the historical period 1980-2016 has been analyzed at hourly scales, seasonal scales and interannual scales. At hourly scales, diurnal wind direction was hovering between South-East and South, and the wind speeds were revealed higher in the afternoon. At monthly-scales, the month of August was revealed to have the highest WS of the year with values above $5.5 \mathrm{~m} \cdot \mathrm{s}^{-1}$. Furthermore, the analysis of the standardized WS index revealed two main parts over the four sites including the period 1980-1996 in low wind speeds and the period 1997-2016 in high wind speeds. Indeed, MK's test detected an upward trend in WS over the period 1980-2016. Moreover, the findings showed that the months June-September are in high WPD with values greater than $60 \mathrm{~W} \cdot \mathrm{m}^{-2}$ while the months November-March are in low WPD with values less than 25 
$\mathrm{W} \cdot \mathrm{m}^{-2}$. Indeed, within the four sites, SIP was revealed to have higher WPD than other sites over the entire baseline period with values greater than $120 \mathrm{~W} \cdot \mathrm{m}^{-2}$ during the summer time.

In the future climate, monthly WS are expected to increase all over the studied sites in both climate scenarios over the periods 2019-2040 and 2071-2100 which will obviously increase WPD. Therefore, following RCP 4.5 over the period 2019-2040, an average WPD change of $28.04 \mathrm{~W} \cdot \mathrm{m}^{-2}, 30.27 \mathrm{~W} \cdot \mathrm{m}^{-2}, 28.15 \mathrm{~W} \cdot \mathrm{m}^{-2}$ and $31.1 \mathrm{~W} \cdot \mathrm{m}^{-2}$ is projected at NHL, NIP, SHL and SIP, respectively. All over the four sites, the month of August is projected to experience the highest WPD change. On the other hand, following RCP 8.5, the month of September is expected to have the highest WPD change all over the study area. The sites NHL, NIP, SHL and SIP are projected to experience WPD changes equal to 28.3 $\mathrm{W} \cdot \mathrm{m}^{-2}, 31.24 \mathrm{~W} \cdot \mathrm{m}^{-2}, 28.42 \mathrm{~W} \cdot \mathrm{m}^{-2}$ and $47.35 \mathrm{~W} \cdot \mathrm{m}^{-2}$, respectively in RCP 8.5. Likewise, over the period 2071-2100 following RCP 4.5, an average WDP change of $83.96 \mathrm{~W} \cdot \mathrm{m}^{-2}, 94.17 \mathrm{~W} \cdot \mathrm{m}^{-2}, 85 \mathrm{~W} \cdot \mathrm{m}^{-2}$ and $116.16 \mathrm{~W} \cdot \mathrm{m}^{-2}$ is respectively projected at NHL, NIP, SHL and SIP. On the other hand, following RCP 8.5, the sites NHL, NIP, SHL and SIP are expected to experience WPD change of 103.82 $\mathrm{W} \cdot \mathrm{m}^{-2}, 116.9 \mathrm{~W} \cdot \mathrm{m}^{-2}, 104.51 \mathrm{~W} \cdot \mathrm{m}^{-2}$ and $152.39 \mathrm{~W} \cdot \mathrm{m}^{-2}$, respectively. Both the scenarios agree on January and September as months expected to experience the lowest and the highest WPD change, respectively over the studied area. They also agreed on SIP as the site expected to experience the highest WPD. The findings highlighted that areas nearby the Lake Tanganyika are expected to experience higher increase in WPD than other areas.

\section{Acknowledgements}

The authors gratefully acknowledge the German Academic Exchange Service (DAAD) for the financial support and all other anonymous contributors to this research work.

\section{Conflicts of Interest}

The authors declare no conflicts of interest regarding the publication of this paper.

\section{References}

[1] Karl, T.R., Melillo, J.M. and Peterson, T.C. (2009) Global Climate Change Impacts in the United States. Cambridge University Press, Cambridge.

[2] IPCC (2007) Towards New Scenarios for Analysis of Emissions, Climate Change, Impacts and Response Strategies. Expert Meeting Report, Noordwijkerhout, The Netherlands.

[3] Brohan, P., Kennedy, J.J., Harris, I., Tett, S.F.B. and Jones, P.D. (2006) Uncertainty Estimates in Regional and Global Observed Temperature Changes: A New Data Set from 1850. Journal of Geophysical Research, 111, 106-126. https://doi.org/10.1029/2005JD006548

[4] Scott, E., James, M., Bart, N. and Wood, A. (2008) Climate Change Effects on Wind 
Speed. North American Windpower, 7, 68-72.

[5] Hasan, M.M. and Wyseure, G. (2018) Impact of Climate Change on Hydropower Generation in Rio Jubones Basin, Ecuador. Water Science and Engineering, 11, 157-166. https://doi.org/10.1016/j.wse.2018.07.002

[6] Deshmukh, M.K. and Moorthy, C. (2013) A New Approach for Prediction of Growth of Onshore Wind Power Potential. International Journal of Electrical \& Electronics Engineering, 3, 107-122.

[7] Parikshit, G.J. and Shrinivas, G.J. (2012) Analysis of Wind Speed Data for Four Locations in Ireland Based on Weibull Distributions Linear Regression Model. International Journal of Renewable Energy Research, 2, 451-455.

[8] Davy, R., Gnatiuk, N., Pettersson, L. and Bobylev, L. (2018) Climate Change Impacts on Wind Energy Potential in the European Domain with a Focus on the Black Sea. Renewable and Sustainable Energy Reviews, 81, 1652-1659.

https://doi.org/10.1016/j.rser.2017.05.253

[9] Schaeffer, R., Szklo, A.S., Pereira, L.A.F., Moreira, C.B.B.S., Pupo, N.L.P., et al. (2012) Energy Sector Vulnerability to Climate Change: A Review. Energy, 38, 1-12. https://doi.org/10.1016/j.energy.2011.11.056

[10] Kainkwa, R.R. (1998) Wind Energy as an Alternative Source to Alleviate the Shortage of Electricity that Prevails during the Dry Season: A Case Study of Tanzania. Renewable Energy, 18, 167-174. https://doi.org/10.1016/S0960-1481(98)00801-5

[11] Peter, N. (2017) Wind Energy: Global and Kenya Prospects and Sustainability Issues. Master's Report, The University of Nairobi, Nairobi, Kenya.

[12] Joel, N., Jackson, N. and Simon, M. (2011) Regional Flow Duration Curve Estimation and Its Application in Assessing Low Flow Characteristics for Ungauged Catchment. A Case Study of Rwegura Catchment-Burundi. Nile Basin Water Sciences \& Engineering Journal, 4, 14-23.

[13] Bamber, P., Guinn, A. and Gereffi, G. (2014) Burundi in the Energy Global Value Chain: Skills of Private Sector Development. Technical Report, CGGC Duke University, NC.

[14] Collins, C., Magnani, R. and Ngomirakiza, E. (2013) Food Security Country Framework for Burundi (FY 2014-FY 2019). USAID, Washington DC.

[15] Lawin, A.E., Manirakiza, C. and Lamboni, B. (2018) Trends and Changes Detection In Rainfall, Temperature and Wind Speed in Burundi. Journal of Water and Climate Change, 155, 1-19. https://doi.org/10.2166/wcc.2018.155

[16] Bidou, J.E., Ndayirukiye, S., Ndayishimiye, J.P. and Sirven, P. (1991) Géographie du Burundi. Hatier, Paris.

[17] MATTE (2014) National Communication Strategy on Adaptation to Climate Change and Precautionary Warning of Extreme Climate Events. Bujumbura, Burundi.

[18] Riaz, V., Kevin, L., Andy, B., Nhlanhla, M. and Bruno, C. (2013) Planning Issues for Newly Industrialized and Developing Countries (Africa). Africa Study Report, CIGRE WG C1.9 Eskom, Johannesburg, South Africa.

[19] Asfaw, A., Simane, B., Hassen, A. and Bantider, A. (2018) Variability and Time Series Trend Analysis of Rainfall and Temperature in Northcentral Ethiopia: A Case Study in Woleka Sub-Basin. Weather and Climate Extremes, 19, 29-41. https://doi.org/10.1016/j.wace.2017.12.002

[20] Ioannis, Z. (2017) Combining Multiple Imputation with Cross-Validation for Cali- 
bration and Assessment of Cox Prognostic Survival Models. Master's Thesis, Leiden University, Leiden, Netherlands.

[21] Giorgi, F., Jones, C. and Asrar, G. (2009) Addressing Climate Information Needs at the Regional Level: The CORDEX Framework. The World Meteorological Organization Bulletin, 58, 175-183.

[22] Riahi, K., Grübler, A. and Nakicenovic, N. (2007) Scenarios of Long-Term Socio-Economic and Environmental Development under Climate Stabilization. Technological Forecasting and Social Change, 74, 887-935. https://doi.org/10.1016/j.techfore.2006.05.026

[23] Liersch, S. and Rivas, R. (2014) Climate Change Report for Burundi. GIZ, Eschborn.

[24] Youm, J.S., Sall, M., Ndiaye, A. and Kane, M.M. (2005) Analysis of Wind Data and Wind Energy Potential Along the Northern Coast of Senegal. Renewable \& Sustainable Energy Reviews, 8, 95-108.

[25] George, Y.L. and David, W.W. (2008) An Adaptive Inverse-Distance Weighting Spatial Interpolation Technique. Computers \& Geosciences, 34, 1044-1055. https://doi.org/10.1016/j.cageo.2007.07.010

[26] Rasmus, E.B., Abdelkader, M. and Kajsa, M.P. (2015) Esd: Climate Analysis and Empirical-Statistical Downscaling (ESD) Package for Monthly and Daily Data. https://github.com/metno/esd

[27] Cannon, A.J. (2016) Multivariate Bias Correction of Climate Model Output: Matching Marginal Distributions and Inter-Variable Dependence Structure. Journal of Climate, 29, 7045-7064. https://doi.org/10.1175/JCLI-D-15-0679.1

[28] RcoreTeam (2018) R: A Language and Environment for Statistical Computing. R Foundation for Statistical Computing, Vienna. https://www.R-project.org/

[29] Cannon, A.J., Sobie, S.R. and Murdock, T.Q. (2015) Bias Correction of Simulated Precipitation by Quantile Mapping: How Well Do Methods Preserve Relative Changes in Quantiles and Extremes? Journal of Climate, 28, 6938-6959. https://doi.org/10.1175/JCLI-D-14-00754.1

[30] Vrac, M. and Willems, P. (2011) Statistical Precipitation Downscaling for Small-Scale Hydrological Impact Investigations of Climate Change. Journal of $\mathrm{Hy}$ drology, 402, 193-205. https://doi.org/10.1016/j.jhydrol.2011.02.030

[31] Berggren, K., Olsson, J., Olofsson, M. and Viklander, M. (2009) Applying Climate Model Precipitation Scenarios for Urban Hydrological Assessment: A Case Study in Kalmar City, Sweden. Atmospheric Research, 92, 364-375. https://doi.org/10.1016/j.atmosres.2009.01.015

[32] Mckee, T.B., Doesken, N.J. and Kleist, J. (1993) The Relationship of Drought Frequency and Duration Times Scales. Proceedings of 8 th Conference on Applied Climatology, Anaheim, CA, 17-22 January, 179-184.

[33] Lawin, A.E., Afouda, A., Gosset, M. and Lebel, T. (2010) Variabilité comparé du régime pluviométrique aux échelles régionale et locales sur la Haute Vallée de l'Ouémé au Bénin. In: Servat, E., Demuth, S., et al., Eds., Global Change: Facing Risks and Threats to Water Resources, International Association of Hydrological Sciences, London, 340.

[34] Soro, G.E., Anouman, D., Goula Bi, T.A. and Srohorou, B. (2014) Characterization of Sequences of Meteorological Dryness at Various Time Scales in Sudanese Climate: Case of the Extreme Northwest of the Ivory Coast. Larhyss Journal, 18, 107-124.

[35] Wilkie, J., Leithead, W.E. and Anderson, C. (1990) Modeling of Wind Turbines by 
Simple Models. Wind Engineering, 14, 247-274.

[36] Manwell, J.F., McGowan, J.G. and Rogers, A.L. (2009) Wind Energy Explained: Theory, Design and Application. Wiley, Chichester. https://doi.org/10.1002/9781119994367

[37] Kendall, M.G. (1962) Rank Correlation Methods. Hafner Publishing Co. Ltd., New York.

[38] Mann, H.B. (1945) Nonparametric Tests against Trend. Econometrica, 13, 245-259. https://doi.org/10.2307/1907187

[39] Rajeevan, M., Bhate, J. and Jaswal, A.K. (2008) Analysis of Variability and Trends of Extreme Rainfall Events over India Using 104 Years of Gridded Daily Rainfall Data. Geophysical Research Letters, 35. https://doi.org/10.1029/2008GL036105

[40] Talaee, P.H. (2014) Iranian Rainfall Series Analysis by Means of Nonparametric Tests. Theoretical and Applied Climatology,116, 597-607. https://doi.org/10.1007/s00704-013-0981-2

[41] Telemu, K. (2013) Trend Analysis of Monthly Rainfall Data in Central Zone. Journal of Mathematics and Statistics, 9, 1-11. https://doi.org/10.3844/jmssp.2013.1.11

[42] Havyarimana, F. (2015) The Contribution of Socio-Political Instability in the Anthropization of Landscapes in Burundi: Spatial Dynamics and Biodiversity. $\mathrm{PhD}$ Thesis, ULB, Bruxels, Belgium.

[43] Mahongo, S.B., Francis, J. and Osima, S.E. (2011) Wind Patterns of Coastal Tanzania: Their Variability and Trends. Western Indian Ocean Journal of Marine Science, 10, 107-120.

[44] ISTEEBU (2017) Annuaire des statistiques de l'environnement. Edition 2016, Bujumbura, Burundi.

[45] Ayodele, T.R., Jimoh, A.A., Munda, J.L. and Agee, J.T. (2013) A Statistical Analysis of Wind Distribution and Wind Power Potential in the Coastal Region of South Africa. International Journal of Green Energy, 10, 814-834.

https://doi.org/10.1080/15435075.2012.727112

[46] Bilal, B.O., Ndongo, M., Sambou, V., Ndiaye, P.A. and Kebe, C.M. (2011) Diurnal Characteristics of the Wind Potential along the North-Western Coast of Senegal. International Journal of Physical Sciencies, 6, 7950-7960.

[47] Bloom, A., Kotroni, V. and Lagouvardos, K. (2008) Climate Change Impact of Wind Energy Availability in the Eastern Mediterranean Using the Regional Climate Model PRECIS. Natural Hazards and Earth System Sciences, 8, 1249-1257. https://doi.org/10.5194/nhess-8-1249-2008

[48] Choge, D.K., Maritim, J.K., Arusei, G.K. and Yegon, G.K. (2013) Small Wind Turbines: A Simulation for Optimal Selection in Uashu-Gishu, Kenya. International Journal of Advanced Research, 1, 508-515. 